\title{
ARTICLE
}

Received 6 Feb 2015 | Accepted 8 Jun 2015 | Published 16 Jul 2015 DOl: 10.1038/ncomms8750

\section{GABA depolarizes immature neurons and inhibits network activity in the neonatal neocortex in vivo}

Knut Kirmse ${ }^{1, \star}$, Michael Kummer ${ }^{1, \star}$, Yury Kovalchuk ${ }^{2}$, Otto W. Witte ${ }^{1}$, Olga Garaschuk ${ }^{2} \&$ Knut Holthoff $^{1}$

\begin{abstract}
A large body of evidence from in vitro studies suggests that GABA is depolarizing during early postnatal development. However, the mode of GABA action in the intact developing brain is unknown. Here we examine the in vivo effects of GABA in cells of the upper cortical plate using a combination of electrophysiological and $\mathrm{Ca}^{2}{ }^{2}$-imaging techniques. We report that at postnatal days (P) 3-4, GABA depolarizes the majority of immature neurons in the occipital cortex of anaesthetized mice. At the same time, GABA does not efficiently activate voltage-gated $\mathrm{Ca}^{2}+$ channels and fails to induce action potential firing. Blocking $\mathrm{GABA}_{A}$ receptors disinhibits spontaneous network activity, whereas allosteric activation of $\mathrm{GABA}_{\mathrm{A}}$ receptors has the opposite effect. In summary, our data provide evidence that in vivo GABA acts as a depolarizing neurotransmitter imposing an inhibitory control on network activity in the neonatal (P3-4) neocortex.
\end{abstract}

\footnotetext{
${ }^{1}$ Hans-Berger Department of Neurology, University Hospital Jena, D-07747 Jena, Germany. ${ }^{2}$ Institute of Physiology II, Eberhard-Karls University Tübingen D-72074 Tübingen, Germany. * These authors contributed equally to this work. Correspondence and requests for materials should be addressed to K.K. (email: knut.kirmse@med.uni-jena.de)
} 
$\gamma$ -Aminobutyric acid (GABA) is the main inhibitory neurotransmitter in the adult brain in $v i v o^{1,2}$. It has long been recognized that $\mathrm{GABA}_{\mathrm{A}}$ receptor $\left(\mathrm{GABA}_{\mathrm{A}} \mathrm{R}\right)$-mediated inhibition involves both conductance-based (shunting) and voltage-based (hyperpolarization) mechanisms. During the last three decades, it became increasingly clear that the latter component is developmentally regulated $^{3}$. Specifically, GABA was shown to depolarize immature neurons in various parts of the central nervous systems of diverse animal species ${ }^{4}$. The developmental depolarizing-to-hyperpolarizing GABA shift is thought to reflect a developmental decline in intracellular chloride concentration $\left(\left[\mathrm{Cl}^{-}\right]_{\mathrm{i}}\right)$ due to a differential expression/ efficacy of plasmalemmal chloride-accumulating (for example $\mathrm{NKCC}^{5-7}$ ) versus chloride-extruding (for example KCC2 (ref. 8) co-transporters ${ }^{9,10}$. By facilitating the generation of action potentials, GABA was further found to promote the generation of patterned network activity ${ }^{3,11-15}$. These data led to the suggestion that GABA, whose synapses assemble before the ones for glutamate ${ }^{16}$, acts as one of the major excitatory neurotransmitters of the developing brain, underlying the activity-dependent growth and differentiation of neurons as well as the assembly of synaptic circuits ${ }^{17-19}$. Owing to an increase in membrane conductance, depolarizing GABAergic inputs may modulate neuronal output in a complex and bidirectional manner. Whether excitatory or inhibitory effects on neuronal firing dominate eventually depends on multiple parameters (including membrane potential, reversal potential of $\mathrm{GABA}_{\mathrm{A}} \mathrm{R}$ mediated currents, action potential threshold ${ }^{20}$, timing and location of inputs ${ }^{21-23}$ as well as previous neuronal activity ${ }^{24,25}$ ).

Although criticism ${ }^{26-28}$ concerning the concept of depolarizing GABA has been largely invalidated in recent years ${ }^{29-33}$, supportive evidence from the intact mammalian brain is still lacking. In favour of a depolarizing GABA action in nonmammalian species in vivo, iontophoretic application of GABA or glycine was found to evoke somatic $\mathrm{Ca}^{2+}$ transients (CaTs) in spinal neurons of zebrafish larvae ${ }^{34}$. In addition, gramicidinperforated patch recordings showed that GABA depolarizes zebrafish retinal ganglion cells at an early developmental stage ${ }^{35}$. At present, only limited information is available on the intact mammalian brain. In agreement with a role for NKCC1 in the generation of neonatal network activity, intraperitoneal injection of the NKCC1 antagonist bumetanide was reported to reversibly abolish hippocampal sharp waves in freely moving rat pups ${ }^{36}$. On the other hand, NKCC1 appears to be dispensable for spindle burst activity in the neonatal rodent somatosensory cortex ${ }^{37}$. Moreover, local blockade of $\mathrm{GABA}_{\mathrm{A}} \mathrm{Rs}$ disinhibited the generation of spindle bursts ${ }^{37}$ but not gamma oscillations ${ }^{38}$, while systemic administration of $\mathrm{GABA}_{\mathrm{A}} \mathrm{R}$ antagonists was found to induce epileptic seizures in neonatal rats ${ }^{39}$.

On the basis of these findings, potential conclusions on cellular GABAergic effects in vivo are limited. Here we directly address the question of whether GABA is depolarizing in vivo in the intact neocortex of living neonatal mice. We focussed on the upper cortical plate (CP) at postnatal days (P) 3-4, since previous investigations from several laboratories have convincingly shown that, in vitro, GABA acts as a predominantly depolarizing neurotransmitter on CP neurons at this age $e^{4,30,31}$. Combining electrophysiological and optical methods with multiple pharmacological manipulations, our results demonstrate that GABA depolarizes the majority of immature neurons in vivo but controls neocortical network activity mainly through inhibition.

\section{Results}

GABA depolarizes the majority of $\mathrm{CP}$ neurons at $\mathrm{P3}-4$ in vivo. To address the question whether GABA depolarizes immature cortical neurons in vivo, we first conducted two-photon-targeted patch-clamp recordings in spontaneously breathing, head-fixed mice at P3-4 under isoflurane anaesthesia. Of note, all cells included in the analysis were identified as neurons on the basis of their ability to generate action potentials (see Methods). Whole-cell voltage-clamp recordings were performed to verify that a 5-s-long pressure application of GABA from an epidurally positioned patch pipette (hereafter referred to as puff application) efficiently activated $\mathrm{GABA}_{\mathrm{A}} \mathrm{Rs}$ in recorded neurons. Indeed, GABA application resulted in a pronounced and completely reversible reduction in membrane resistance from $749 \pm 104$ to $46 \pm 10 \mathrm{M} \Omega$ (one-way repeated-measures analysis of variance (ANOVA), with Huynh-Feldt correction: $P<0.001, \quad n=9$ neurons, $\eta_{\mathrm{p}}^{2}=0.84$; control versus GABA: $P<0.001$, GABA versus washout: $P<0.01$, control versus washout: $P>0.95$, post hoc Bonferroni-corrected pairwise comparisons; Fig. 1a,b). In a separate set of experiments, we then asked whether the same application protocol is suited to initiate action potential firing in CP cells. Using cell-attached recordings in loose-seal $(n=7)$ and tight-seal $(n=5$; seal resistance $>1 \mathrm{G} \Omega$ ) voltage-clamp modes, none of the tested neurons displayed action currents in response to puff-applied GABA, whereas all cells showed robust burst firing in response to puff-applied glutamate (Fig. 1c,d). Accordingly, the following experiments were carried out in the absence of voltage-gated $\mathrm{Na}^{+}$channel antagonists. To non-invasively assess the polarity of GABA-induced membrane potential changes, we next used cell-attached current-clamp recordings ${ }^{30,40}$. Among 15 neurons recorded $(n=12$ cells in the $\mathrm{CP}, n=3$ cells in the marginal zone), puff-applied GABA induced monophasic membrane depolarization in 10 neurons (Fig. 1e,f and Supplementary Fig. 1). Hyperpolarization in response to GABA was observed in two cells (one of which displayed a biphasic, initially hyperpolarizing, then depolarizing response; corresponding to cell 10 in Fig. 1f), and inconsistent responses with a tendency towards depolarization were found in an additional three cells (cells 6, 11 and 12 in Fig. 1f). The mean change in the measured potential amounted to $+6.7 \pm 1.5 \mathrm{mV}$ and differed significantly from zero $(n=15$ cells, $P<0.001$, one-sample $t$-test on null hypothesis: mean $=0$ ). Additional experiments at $\mathrm{P} 25-27$ revealed that $\mathrm{GABA}_{\mathrm{A}} \mathrm{R}$ activation in the presence of the membrane-permeable carbonic anhydrase inhibitor 6-ethoxy-2-benzothiazolesulfonamide (EZA; $150 \mu \mathrm{M})$ failed to induce membrane depolarization in the majority of layer 2/3 neurons in juvenile mice (P25-27: $\Delta V=+1.2 \pm 1.2 \mathrm{mV}$, $n=10$; P3-4: $\Delta V=+6.7 \pm 1.5 \mathrm{mV}, n=15 ; P<0.05$, two-sample $t$-test; Supplementary Fig. 2). On the basis of direct electrophysiological evidence, we hence conclude that GABA depolarizes the majority of immature CP neurons at P3-4.

Lack of GABA-induced somatic CaTs at P3-4. Previous studies in neocortical brain slices have repeatedly demonstrated that activation of $\mathrm{GABA}_{\mathrm{A}} \mathrm{Rs}$ can trigger a depolarization-dependent rise in intracellular free $\mathrm{Ca}^{2+}$ concentration $\left(\left[\mathrm{Ca}^{2+}\right]_{\mathrm{i}}\right)$ in immature neurons $s^{5,13,30,41}$. To investigate whether the same mechanism is functional in vivo, we next used two-photon $\mathrm{Ca}^{2+}$ imaging in the upper CP (Fig. 2a,b). In an initial set of experiments, mice were administered the analgesic-sedative nitrous oxide to circumvent (I) potential complications of conventional anaesthetics (which are known to interfere with the generation of large-scale $\mathrm{Ca}^{2}+$ waves in rodent pups ${ }^{42,43}$ ) or (II) recordings in unanaesthetized mice ${ }^{44}$. In agreement with the observed lack of GABA-induced action potential firing (see above), we found that puff application of GABA (100 mM, for definition of the application time see Methods) from an epidurally positioned pipette mostly failed to evoke distinct 

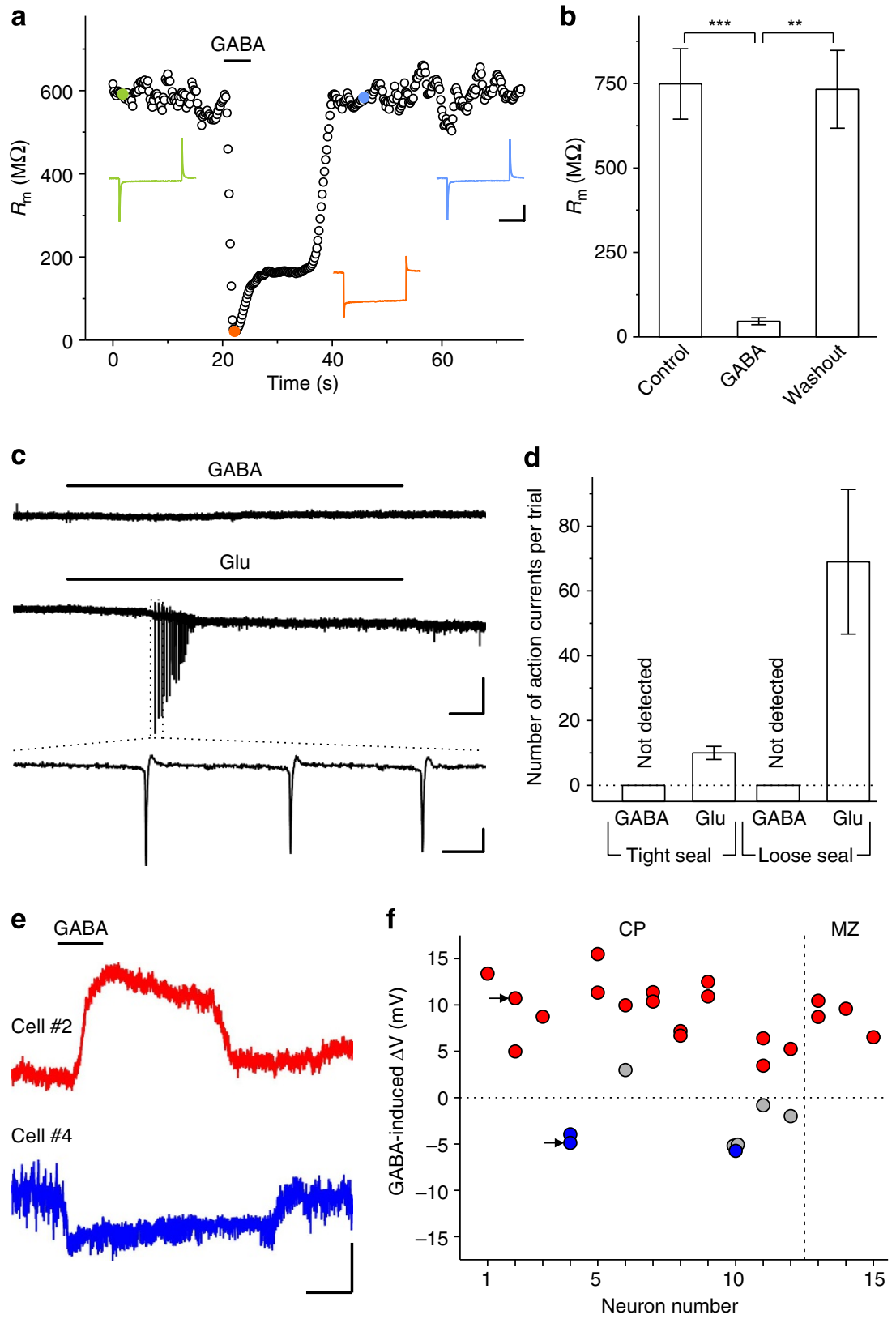

Figure 1 | GABAergic depolarization in immature neocortical neurons in vivo. (a) Sample time course of membrane resistance $\left(R_{\mathrm{m}}\right.$, moving average over five trials) in response to GABA $(100 \mathrm{mM}, 5 \mathrm{~s})$ puff-applied from an epidural pipette. Current responses to hyperpolarizing voltage steps (-10 mV) are shown as insets. Scale bars, 100 pA, 20 ms. (b) Quantification $(n=9$, cells one-way repeated-measures ANOVA, Huynh-Feldt-corrected: $P<0.001$; post hoc Bonferroni-corrected pairwise comparisons: control-GABA: $P<0.001$, GABA-washout: $P<0.01$, control-washout: $P>0.95$ ). (c) Cell-attached voltageclamp recordings from a single neuron sequentially exposed to GABA (top; $100 \mathrm{mM}, 5 \mathrm{~s}$ ) and glutamate (Glu, bottom; $100 \mathrm{mM}, 5 \mathrm{~s}$ ). Scale bars,

$20 \mathrm{pA}, 500 \mathrm{~ms}$ (top) and $15 \mathrm{pA}, 15 \mathrm{~ms}$ (bottom). (d) Number of action currents per trial in response to GABA and glutamate in tight-seal ( $n=5)$ and looseseal $(n=7)$ configurations. (e) Cell-attached current-clamp recordings obtained from two different neurons show that puff-applied GABA (100 mM, $5 \mathrm{~s}$ ) evoked depolarization (cell \#2) and hyperpolarization (cell \#4), respectively. Scale bars, $5 \mathrm{mV}, 5 \mathrm{~s}$. (c,e) Electromagnetic artefacts due to valve opening/closure were clipped for clarity. (f) Quantification. Each cell was tested in one to three trials. Each symbol represents a single trial. Depolarizing responses are indicated by red symbols, hyperpolarizing responses by blue symbols. Grey-shaded symbols refer to trials with amplitudes lower than three times the s.d. of the baseline noise. Arrows point to trials shown in e. CP, cortical plate ( $n=12$ cells); MZ, marginal zone $(n=3$ cells). (b,d) Data presented as mean \pm s.e.m. ${ }^{\star \star} P<0.01,{ }^{\star \star \star} P<0.001$.

somatic CaTs in glutamate-responsive cells (Fig. 2c). At P3-4, the GABA-induced relative change in fluorescence $\left(\Delta F / F_{0}\right)$ amounted to $0.01 \pm 0.00(P>0.15, n=204$ cells from five mice, one-sample Wilcoxon-signed rank test on null hypothesis: median $=0$; Fig. 2d). On the basis of a $\Delta F / F_{0}$ threshold criterion (see Methods), one out of 204 cells was classified as responsive to GABA. Similar results were obtained when the duration of the
GABA puff was prolonged by a factor of five (six out of 204 cells were classified as responsive to GABA; $\Delta F / F_{0}=0.01 \pm 0.01$, $P>0.95, n=204$ cells, one-sample Wilcoxon-signed rank test). Subsequent to the in vivo experiments, acute brain slices comprising the stained region were prepared and the experiment was repeated in vitro (Supplementary Fig. 3a-f). To reduce differences in effective concentrations of GABA and 
a

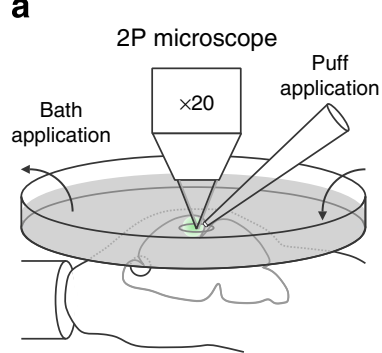

b

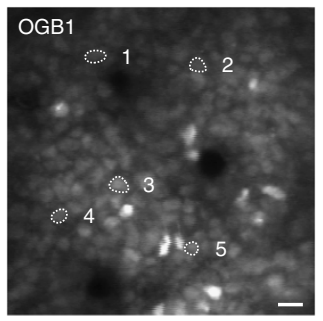

C

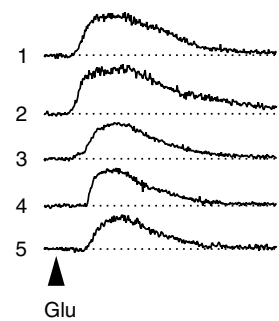

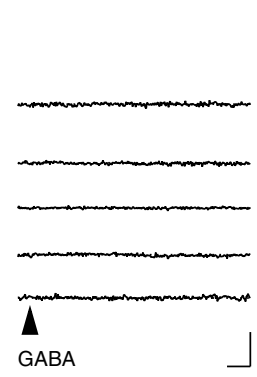

d

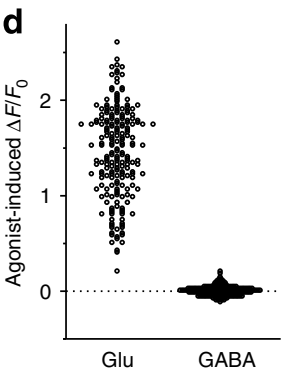

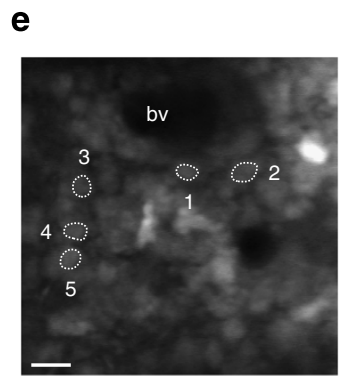
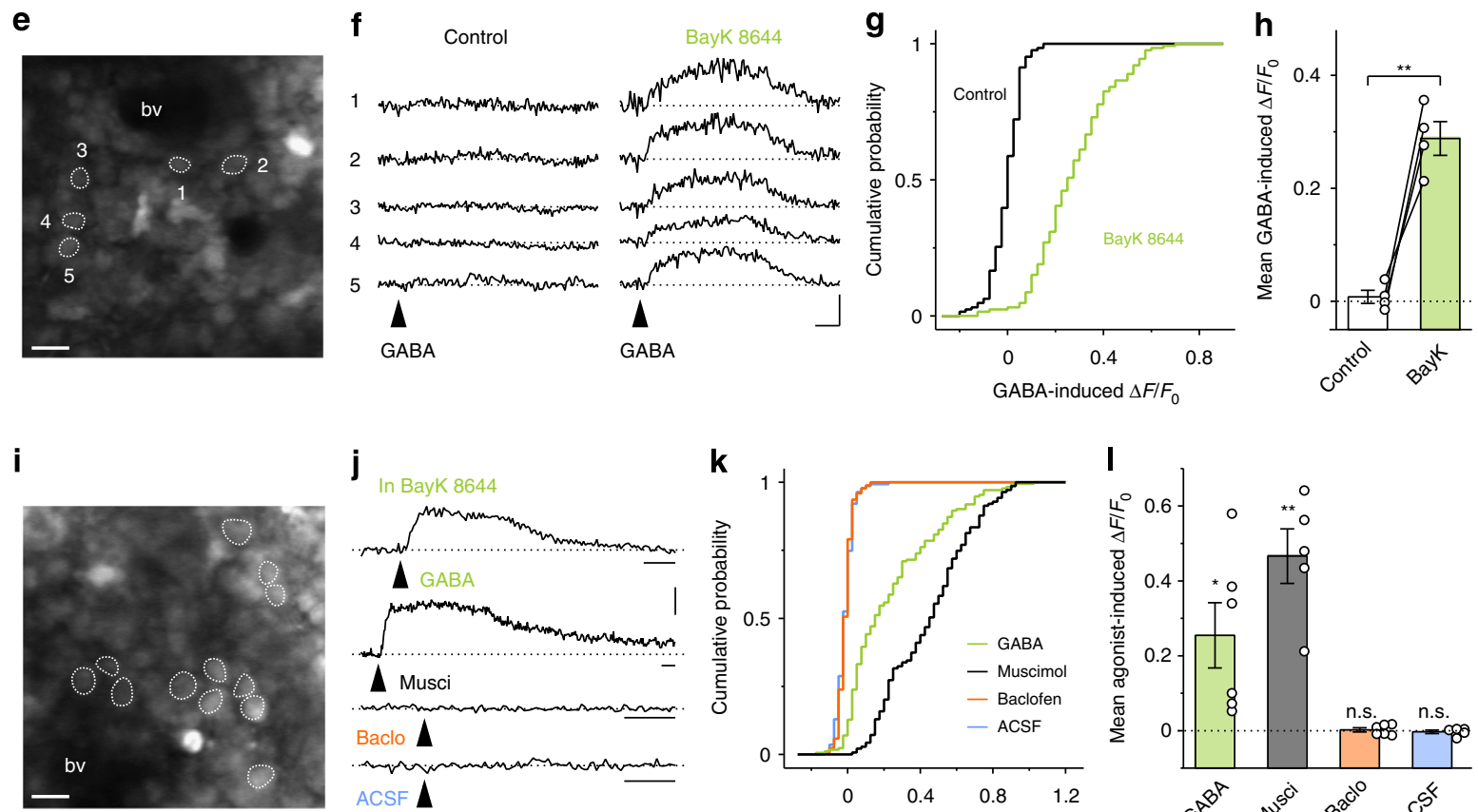

j
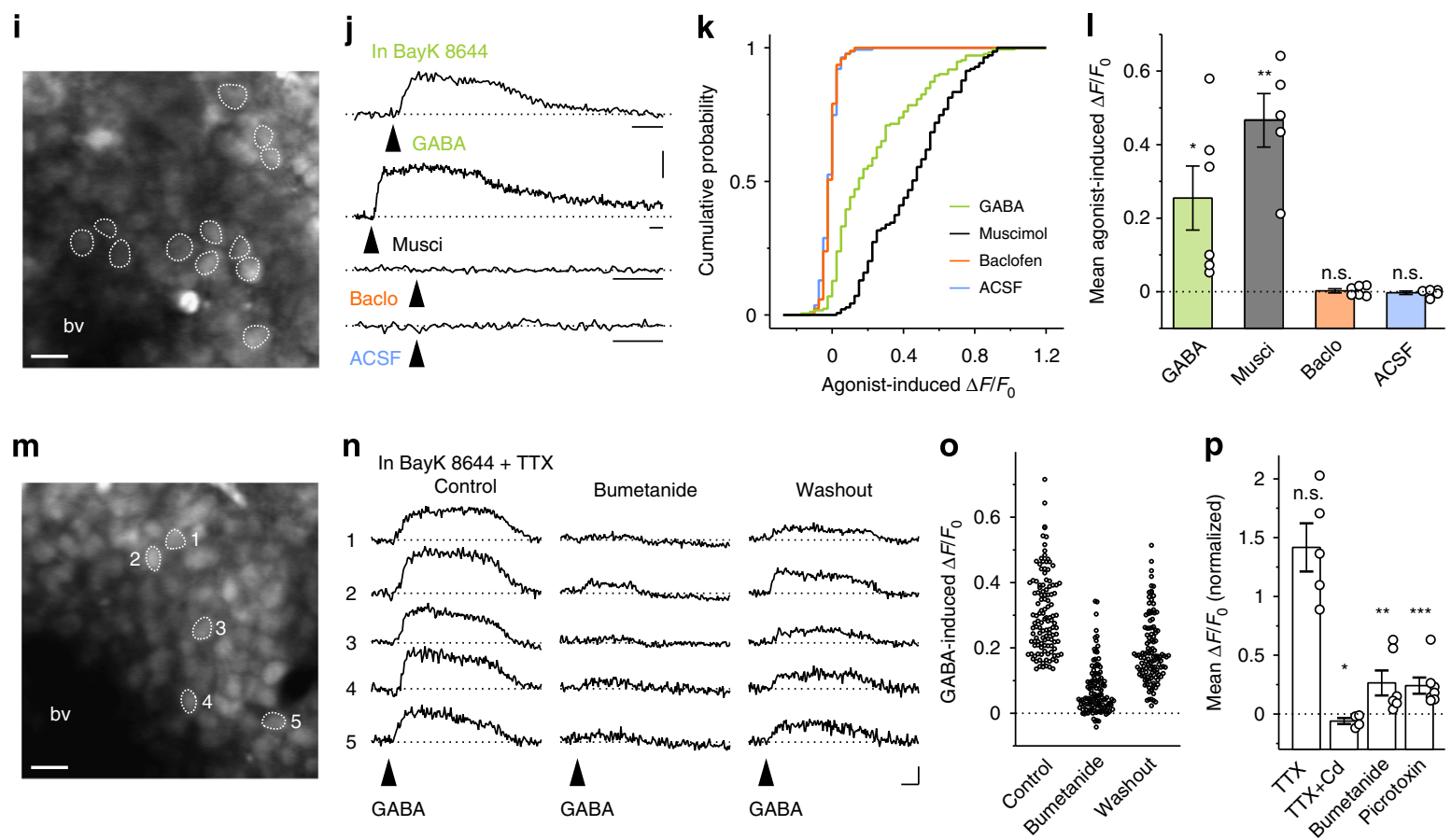

Figure 2 | GABA-induced somatic $\mathbf{C a}^{2}+$ transients in the presence of BayK 8644 in vivo. (a) Experimental arrangement. (b,e,i,m) Two-photon fluorescence images of OGB1-stained CP cells in vivo. Scale bars, $10 \mu \mathrm{m}$; bv, blood vessel. (c) Single-cell $\mathrm{Ca}^{2+}$ responses to puff-applied glutamate (Glu; $100 \mathrm{mM}, 0.3 \mathrm{~s})$ and GABA $(100 \mathrm{mM}, 0.3 \mathrm{~s})$. Scale bars, $1.5 \Delta F / F_{0}, 2.5 \mathrm{~s}$. (d) $\Delta F / F_{0}$ amplitude distributions. Each symbol represents a single cell $(n=204$ cells, five mice). (f) GABA-induced $\mathrm{Ca}^{2+}$ responses in the absence (Control) and presence of BayK $8644(20 \mu \mathrm{M}) . \mathrm{Scale}$ bars, $0.5 \Delta F / F_{0}, 5 \mathrm{~s}$. (g) $\Delta F / F_{0}$ amplitude distributions ( $n=126$ cells, four mice). (h) The mean $\Delta F / F_{0}$ amplitudes per animal $\left(P<0.01, n=4\right.$ mice, paired $t$-test). (j) Ca ${ }^{2+}$ responses (averages from 12 cells shown in $\mathbf{i}$ ) to GABA (100 mM), Muscimol (Musci, $5 \mathrm{mM}$ ), Baclofen (Baclo, $5 \mathrm{mM}$ ) and ACSF. Note differences in time-axis scaling. Scale bars, $0.25 \Delta F / F_{0}, 5 \mathrm{~s}$. (k) $\Delta F / F_{0}$ amplitude distributions (GABA: $n=172$ cells; Muscimol: $n=139$ cells; Baclofen: $n=172$ cells; ACSF: $n=139$ cells). (I) The mean $\Delta F / F_{0}$ amplitudes per animal (GABA: $P<0.05, n=6$ mice; Muscimol: $P<0.01, n=5$ mice; Baclofen: $P>0.95, n=6$ mice; ACSF: $P>0.4, n=5$ mice; one-sample Wilcoxon-signed rank tests). (n) GABA-induced $\mathrm{Ca}^{2}+$ responses were sensitive to bumetanide $(50 \mu \mathrm{M}) . \mathrm{Scale}$ bars, $0.25 \Delta F / F_{0}, 5 \mathrm{~s}$. (o) Single-cell GABA-induced $\Delta F / F_{0}$ amplitude distributions $\left(n=122\right.$ cells, six mice). ( $(p)$ The mean $G A B A$-induced $\Delta F / F_{0}$ amplitudes per animal (normalized to control). GABA-induced $\mathrm{Ca}^{2}+$ transients did not require voltage-gated $\mathrm{Na}^{+}$channels (TTX: $P>0.15, n=5$ mice) but were sensitive to antagonists of voltage-gated $\mathrm{Ca}^{2}+$ channels (TTX $+\mathrm{CdCl}_{2}: P<0.05, n=4$ mice, Bonferroni-corrected paired $t$-tests), NKCC1 (Bumetanide: $n=6 ;$ repeated-measures ANOVA: $P<0.001$, Bonferroni test: $P<0.01$ ) and $\mathrm{GABA}_{\mathrm{A}}$ receptors (Picrotoxin: $P<0.001, n=7$; paired $t$-test). Picrotoxin and bumetanide were tested in the presence of TTX. (i-p) Experiments were performed in the presence of BayK 8644. (h,l,p) Data presented as mean \pm s.e.m. ${ }^{\star} P<0.05$, ${ }^{\star \star} P<0.01$, ${ }^{\star \star \star} P<0.001$, n.s., not significant. 
glutamate reaching the cells of interest, pipette concentrations of agonists were reduced $(1 \mathrm{mM})$ and application times were adjusted such that amplitudes of glutamate-induced CaTs in vitro matched those in vivo $\left(\Delta F / F_{0}\right.$ in vivo: $1.45 \pm 0.03, n=204$ cells, $\Delta F / F_{0}$ in vitro: $1.46 \pm 0.02, n=407$ cells from 10 slices and five mice, $P>0.45$, Mann-Whitney $U$-test; Supplementary Fig. 3e,f). In line with data from naive slices ${ }^{13,30}$, puff-applied GABA triggered significant $\mathrm{CaTs}$ in glutamate-responsive cells (GABA-induced $\Delta F / F_{0}: 0.40 \pm 0.01, P<0.001, n=407$ cells from 10 slices and five mice, one-sample Wilcoxon-signed rank test on null hypothesis: median $=0$; Supplementary Fig. $3 \mathrm{c}-\mathrm{f}$ ). When normalized to glutamate response amplitudes, GABA-induced $\Delta F / F_{0}$ values differed significantly between cells within intact cortex and slice, respectively (in vivo: $0.00 \pm 0.00, n=204$ cells, in vitro: $0.29 \pm 0.01, n=407$ cells, $P<0.001$, Mann-Whitney $U$-test). We next examined the effects of lower GABA concentrations (1 and $10 \mathrm{mM}$ ) and/or shorter application times (10\% of $t_{\text {short }}$; see Methods) under isoflurane anaesthesia. However, GABA-induced somatic CaTs were not detected under these conditions $\left(10 \mathrm{mM}\right.$ and $t_{\text {short }}: \Delta F / F_{0}=0.00 \pm 0.01$; $10 \mathrm{mM}$ and $10 \%$ of $t_{\text {short: }}: \Delta F / F_{0}=0.00 \pm 0.00 ; 1 \mathrm{mM}$ and $t_{\text {short }}: \Delta F / F_{0}=-0.02 \pm 0.01 ; \quad 1 \mathrm{mM}$ and $10 \%$ of $t_{\text {short }}$ : $\Delta F / F_{0}=-0.01 \pm 0.00$; none out of 44 cells from two mice was classified as responsive to GABA). Collectively, our data suggest that in vivo GABA does not efficiently activate voltage-gated $\mathrm{Ca}^{2+}$ channels (VGCCs) at P3-4.

For comparison, additional experiments were performed at P1 $\left(n=3\right.$ mice). Using the standard puff application duration $\left(t_{\text {short }}\right)$, 11 out of 117 cells (9.4\%) were found to be responsive to GABA (versus 1 out of 204 cells $(0.5 \%)$ at P3-4: $P<0.001$, Pearson's $\chi^{2}$-test) and GABA-induced $\Delta F / F_{0}$ amplitudes differed significantly from zero $\left(\Delta F / F_{0}=0.07 \pm 0.01, P<0.001\right.$, onesample Wilcoxon-signed rank test; Supplementary Fig. 4). Similar results were obtained when the duration of the GABA puff was prolonged by a factor of five $\left(\Delta F / F_{0}=0.06 \pm 0.01, P<0.001\right.$, one-sample Wilcoxon-signed rank test; 11 out of 117 cells were classified as responsive to GABA at P1 versus 6 out of 204 cells at P3-4: $P=0.013$, Pearson's $\chi^{2}$-test; Supplementary Fig. 4). These data show that (I) a significantly larger fraction of cells is responsive to GABA at P1 as compared with $\mathrm{P} 3-4$ and, at the same time, (II) the vast majority of cells $(>90 \%)$ are nonresponsive to GABA in both age groups.

GABA-evoked CaTs in presence of BayK 8644 at P3-4. Previous investigations in acute brain slices revealed that GABA-mediated CaTs in CP cells mainly involve L-type VGCCs ${ }^{5}$ whose activation threshold is considerably more positive than typical resting membrane potentials. Consequently, even moderate depolarizations might not affect $\left[\mathrm{Ca}^{2+}\right]_{i}$. We therefore aimed at increasing the detection sensitivity for depolarization by enhancing the VGCC-mediated $\mathrm{Ca}^{2+}$ flux. To this end, we used BayK 8644, a well-characterized positive modulator of L-type VGCCs known to increase their mean open time and to shift the voltage dependence of activation towards more negative potentials ${ }^{45}$. In naive neocortical slices at P3-4, and in line with data from the olfactory bulb ${ }^{46}$, we found that BayK $8644(20 \mu \mathrm{M})$ consistently increased the amplitude of GABA-induced CaTs in the upper $\mathrm{CP}\left(\Delta F / F_{0}\right.$ in control: $0.35 \pm 0.09, \Delta F / F_{0}$ in BayK 8644: $0.79 \pm 0.07, P<0.01, n=5$ slices, paired $t$-test; Supplementary Fig. $3 \mathrm{~g}-\mathrm{j})$. We next analysed the effect of BayK $8644(20 \mu \mathrm{M})$ in vivo by superfusion of the exposed dura mater (hereafter referred to as bath application). We found that bath-applied BayK 8644 unmasked GABAinduced CaTs in vivo. The mean GABA-induced $\Delta F / F_{0}$ values in glutamate-responsive cells were $0.01 \pm 0.01$ in control and
$0.29 \pm 0.03$ in the presence of BayK $8644(P<0.01, n=4$ mice with 126 cells, paired $t$-test; Fig. 2e-h).

We next examined whether CaTs induced by epidural puff application of GABA in the presence of BayK 8644 were sensitive to the conventional anaesthetic isoflurane. On average, amplitudes of GABA-mediated CaTs were not significantly affected $\left(\mathrm{N}_{2} \mathrm{O}: 0.28 \pm 0.04\right.$, isoflurane plus $\mathrm{N}_{2} \mathrm{O}: 0.24 \pm 0.17$, $P>0.8, n=3$ mice with 92 cells, paired $t$-test). Since the addition of isoflurane increased mechanical recording stability, we used the latter anaesthetic regime for further pharmacological characterizations. In glutamate-responsive cells and in the presence of BayK 8644, GABA-mediated CaTs $\left(\Delta F / F_{0}: 0.25 \pm 0.09, P<0.001\right.$, $n=6$ mice with 172 cells) were mimicked by the specific $\mathrm{GABA}_{\mathrm{A}} \mathrm{R}$ agonist muscimol $\left(5 \mathrm{mM} ; \Delta F / F_{0}: 0.47 \pm 0.07, P<0.001\right.$, $n=5$ mice with 139 cells, one-sample Wilcoxon-signed rank tests on null hypothesis: median $=0$; Fig. $2 \mathrm{i}-1$ ). In these experiments, the fraction of agonist-responsive cells (defined as $\Delta F / F_{0}$ larger than three times the s.d. of single-cell amplitudes in response to puff-applied artificial cerebrospinal fluid (ACSF), that is, $\Delta F / F_{0}>0.13$ ) was $55 \%$ for GABA and $95 \%$ for muscimol. As expected, GABA- and muscimol-induced $\Delta F / F_{0}$ values displayed a significant positive correlation (Spearman's $\rho=0.67$, $P<0.001, n=90$ cells, only GABA-responsive cells included; Supplementary Fig. 5). In contrast, CaTs were not observed in response to the specific $\mathrm{GABA}_{\mathrm{B}}$ receptor agonist baclofen $(5 \mathrm{mM}$; $\Delta F / F_{0}: 0.00 \pm 0.01, P>0.95, n=6$ mice with 172 cells) or ACSF alone $\left(\Delta F / F_{0}:-0.00 \pm 0.00, P>0.4, n=5\right.$ mice with 139 cells, one-sample Wilcoxon-signed rank tests on null hypothesis: median $=0$; Fig. 2j-1). Furthermore, in GABA-responsive cells, GABA-mediated CaTs were not reduced in amplitude by the voltage-gated $\mathrm{Na}^{+}$channel blocker tetrodotoxin (TTX, $3 \mu \mathrm{M}$; $\Delta F / F_{0}: 142 \pm 21 \%$ of control, $P>0.15, n=5$ mice with 102 cells; Fig. 2p), suggesting that action potential-dependent network excitation did not contribute to their generation. By contrast, GABA-mediated CaTs were completely abolished by the subsequent addition of the broad-spectrum VGCC antagonist $\mathrm{CdCl}_{2}(200-300 \mu \mathrm{M})$, indicating the dependence on depolarization $\left(\Delta F / F_{0}:-5.9 \pm 2.6 \%\right.$ of control, $n=4$ mice with 82 cells, $P<0.05$, paired $t$-tests with Bonferroni correction; Fig. $2 p)$. In neocortical neurons in vitro, the $\mathrm{Na}^{+} / \mathrm{K}^{+} / 2 \mathrm{Cl}^{-}$co-transporter NKCC1 was previously shown to maintain $\left[\mathrm{Cl}^{-}\right]_{\mathrm{i}}$ above passive distribution $^{5,12,18}$. In agreement with this, we found that bath application of the NKCC1 inhibitor bumetanide $(50 \mu \mathrm{M})$ reduced the amplitudes of GABA-mediated CaTs in GABA-responsive cells to $26 \pm 11 \%$ that partially recovered to $67 \pm 9.0 \%$ during washout (one-way repeated-measures ANOVA: $P<0.001, n=6$ mice with 122 cells, $\eta_{\mathrm{p}}^{2}=0.86$; control versus bumetanide: $P<0.01$; bumetanide versus washout: $P<0.01$, post hoc Bonferroni-corrected pairwise comparisons; Fig. $2 \mathrm{~m}-\mathrm{p}$ ). The latter experiments were conducted in the presence of TTX to inhibit recurrent excitation. Involvement of $\mathrm{GABA}_{\mathrm{A}} \mathrm{Rs}$ was further corroborated by the observation that bath-applied $\mathrm{GABA}_{\mathrm{A}} \mathrm{R}$ antagonist picrotoxin $(250 \mu \mathrm{M})$ strongly reduced the amplitudes of GABA-evoked CaTs to $24 \pm 6.8 \%(P<0.001, n=7$ mice with 111 cells, paired $t$-test; four of seven mice were previously exposed to bumetanide; Fig. $2 p$ ). Collectively, these data provide evidence for a depolarizing effect of $G_{A B A} R$ activation in the majority of $\mathrm{CP}$ cells in vivo at $\mathrm{P} 3-4$.

Synaptic excitation depends on glutamatergic input. We next sought to determine whether GABAergic synaptic activity is able to trigger action potential discharge in immature cortical cells. To address this question, we applied repetitive electrical stimulation $(25$ pulses, $50 \mathrm{~Hz}$ ) via a low-resistance glass electrode positioned in the upper CP. First, we used two-photon $\mathrm{Ca}^{2+}$ imaging 
(Fig. 3a,b) as a secondary readout of action potential firing ${ }^{47}$. With both GABAergic and glutamatergic transmission intact, electrical stimulation induced somatic CaTs in the vast majority of cells examined (70 out of 73 cells from three mice; 45 of these cells responded during each of three trials; Fig. 3c). Bath application of ionotropic glutamate receptor antagonists (50 $\mathrm{MM}$ 6,7-dinitroquinoxaline-2,3(1H,4H)-dione (DNQX) plus $250 \mu \mathrm{M}$ DL-2-amino-5-phosphonopentanoic acid (APV)) blocked stimulation-induced CaTs in all cells except one (cell \#49; Fig. 3c). The latter was probably activated in an antidromic manner since responses persisted even in the additional presence of the $\mathrm{GABA}_{\mathrm{A}} \mathrm{R}$ antagonist gabazine $(40 \mu \mathrm{M})$. These data suggest that GABAergic afferent stimulation alone is insufficient to induce somatic CaTs in upper CP cells. In line with this conclusion, local puff application of GABA from a pipette positioned within the $\mathrm{CP}$ also failed to induce somatic CaTs in upper CP cells (Supplementary Fig. 6).

Single action potentials might escape detection in OGB1-based $\mathrm{Ca}^{2+}$ imaging experiments ${ }^{47}$. We therefore performed additional two-photon-guided cell-attached recordings in the upper CP. All cells included in the analysis were identified as neurons on the basis of their ability to generate action potentials. With both GABAergic and glutamatergic transmission intact, repetitive electrical stimulation (25 pulses, $50 \mathrm{~Hz})$ triggered action potential firing in four out of five neurons (Fig. 3d-f). The average number of action currents per trial and cell amounted to $4.9 \pm 1.7$ ( $n=5$ neurons; Fig. $3 \mathrm{~g}$ ). In contrast, in the presence of DNQX plus APV, electrical stimulation failed to initiate action potential firing in all neurons examined $(n=7$ neurons; Fig. 3d-g). In summary, we conclude that synaptically driven action potential firing at $\mathrm{P} 3-4$ in vivo is largely dependent on glutamatergic, but not GABAergic, input.

Spontaneous neocortical network activity in vivo. We next aimed at elucidating how GABA contributes to the generation of cortical network activity. To this end, we performed wide-field epifluorescence $\mathrm{Ca}^{2}+$ imaging in mice (P3-4) expressing the genetically encoded $\mathrm{Ca}^{2+}$ indicator GCaMP3 in cortical glutamatergic cells $\left(E m x 1^{\text {IREScre }}: G C a M P 3^{L S L} \text { mice }\right)^{43,48,49}$ (Fig. 4a,b). For analysis, the field of view $\left(\sim 1 \mathrm{~mm}^{2}\right)$ was

Figure 3 | Lack of somatic $\mathrm{Ca}^{2}+$ transients and action potential discharge in response to GABAergic afferent stimulation in vivo. (a) Twophoton fluorescence image of OGB1-stained CP cells in vivo after positioning of an extracellular stimulation electrode (stim). Scale bar, $50 \mu \mathrm{m}$. (b) Field of view during recording as indicated by a dashed rectangle in a. Scale bar, $10 \mu \mathrm{m}$. (c) Top: for both single trials and averaged traces cells were independently classified as responsive (red) or unresponsive (blue) based on an amplitude-threshold criterion. Each stimulation trial consisted of 25 pulses delivered at $50 \mathrm{~Hz}$. All cells included were tested in standard ACSF (Control, left), in the presence of DNQX $(50 \mu \mathrm{M})$ plus APV $(250 \mu \mathrm{M}$, middle) as well as in the presence of DNQX plus APV plus Gabazine ( $40 \mu \mathrm{M}$, right). Bottom: sample traces from five cells indicated in $\mathbf{b}$. Note that DNQX plus APV blocked responses in all cells except one (\#49). Scale bars, $0.5 \Delta F / F_{0}, 1 \mathrm{~s}$. (d) Cell-attached voltage-clamp recordings from two different neurons in standard ACSF (Control) and in the presence of DNQX plus APV, respectively. Each repetitive electrical stimulation trial consisted of 25 pulses delivered at $50 \mathrm{~Hz}$. Stimulation artefacts were blanked for clarity (grey bars). Action currents (ACs) are indicated by red vertical lines. Scale bars, 25 pA, $100 \mathrm{~ms}$. (e) Summary plot of excited (red) and nonexcited (blue) neurons ( $n=5$ cells in control, $n=7$ cells in DNQX plus APV). (f) Absolute number of excited and non-excited neurons. ( $(\mathbf{g})$ The mean number of action currents per neuron and trial. Data presented as mean \pm s.e.m. subdivided into a regular grid of regions of interest (ROI; Fig. $4 \mathrm{c}$ ). When mice were anaesthetized with $\mathrm{N}_{2} \mathrm{O}$, spontaneous network activity occurred in the form of spatiotemporal clusters of CaTs in all animals examined $(n=21$ mice; Fig. $4 \mathrm{~b}-\mathrm{d}$ and Supplementary Movie 1). Single-cell two-photon $\mathrm{Ca}^{2}+$ imaging in Emx $1^{I R E S c r e}: G C a M P 3^{L S L}$ mice confirmed that $\mathrm{Ca}^{2+}$ cluster
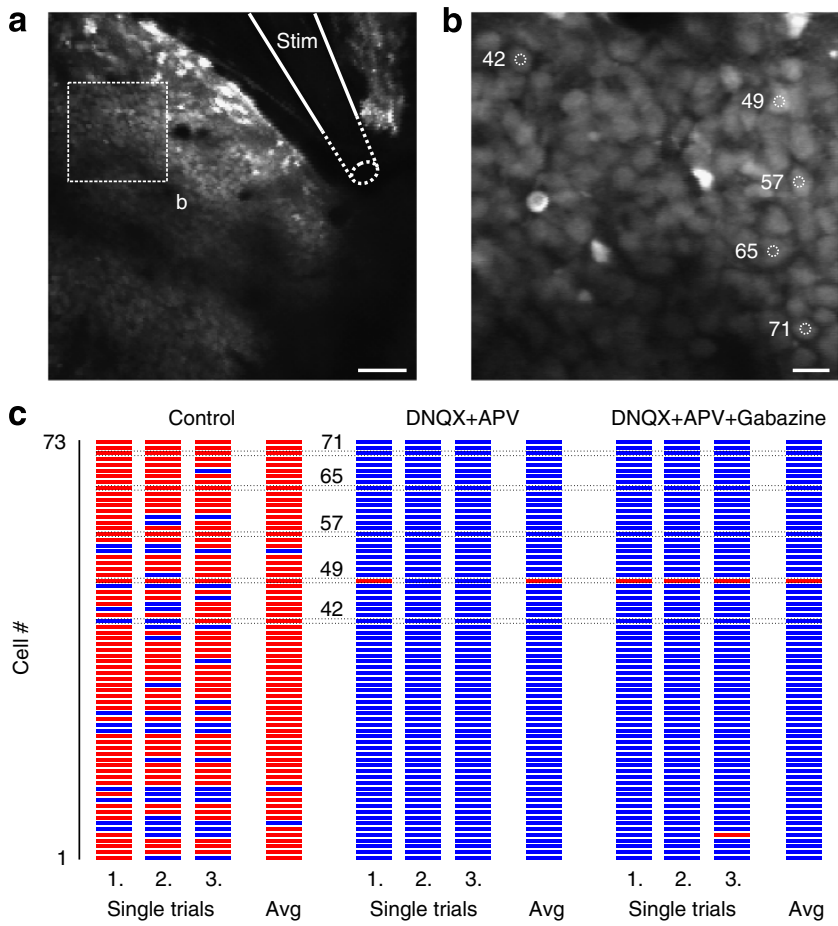

Control
DNQX+APV

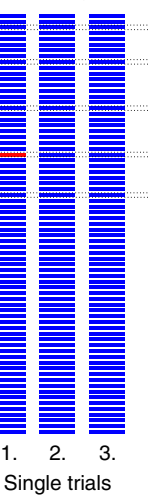

$\mathrm{DNQX}+\mathrm{APV}+\mathrm{Gabazine}$

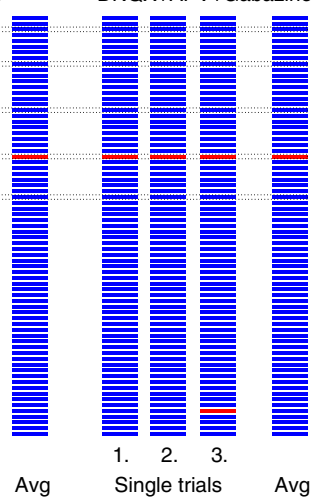

— Responsive — Unresponsive

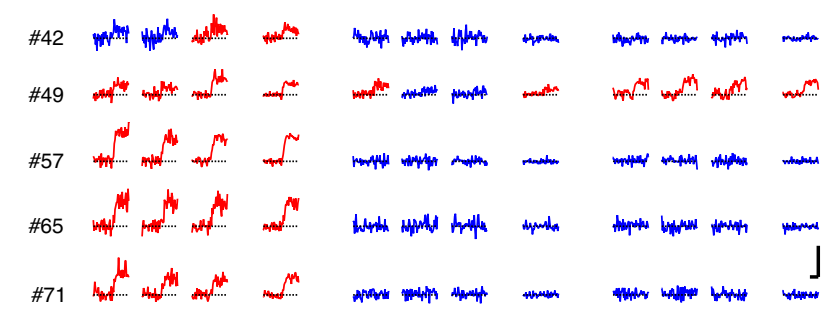

d

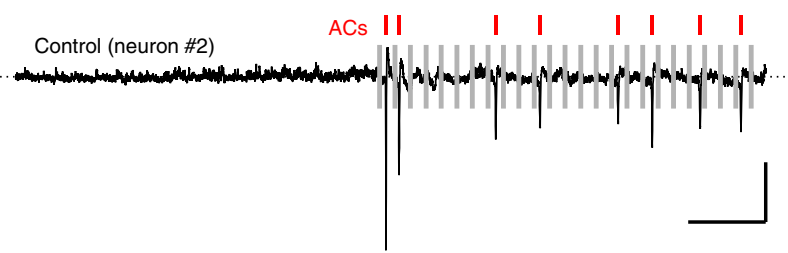

DNQX+APV (neuron \#3)
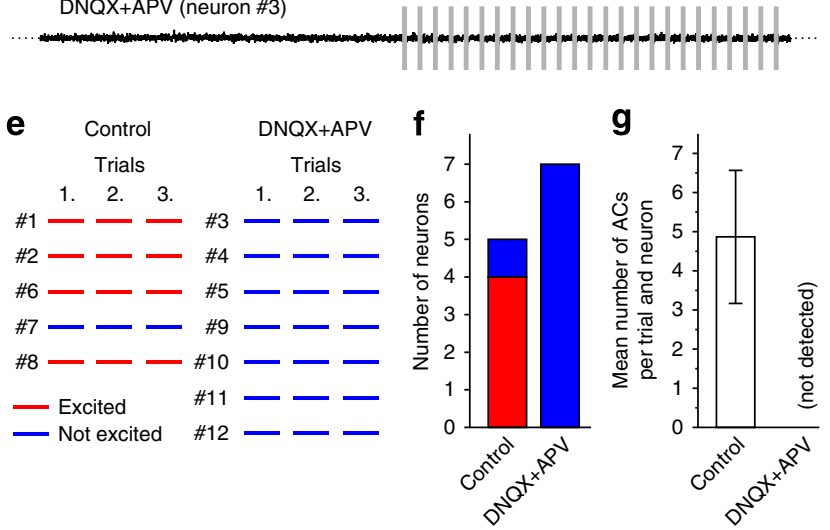
a

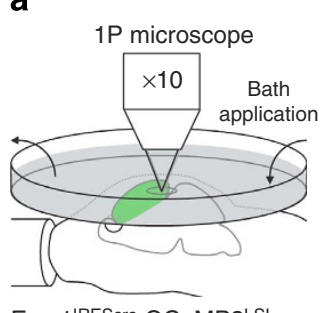

Emx1/REScre:GCaMP3LSL

e

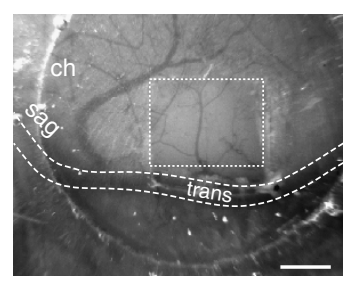

b

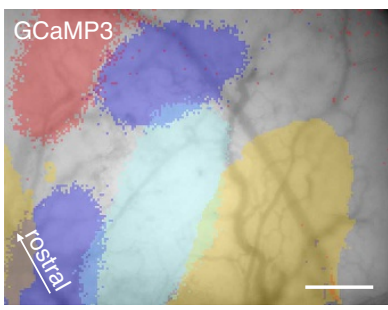

f

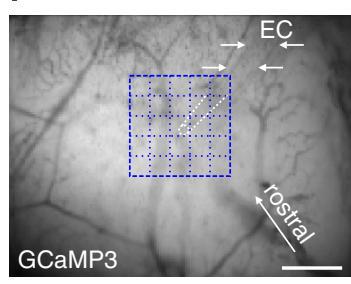

C

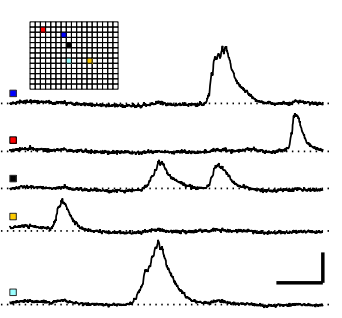

g d

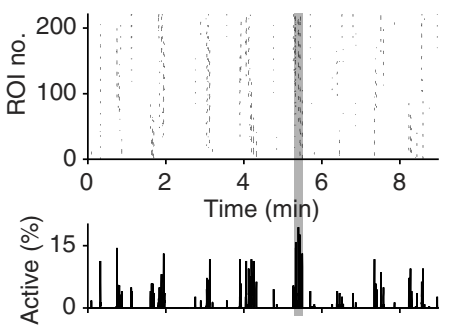

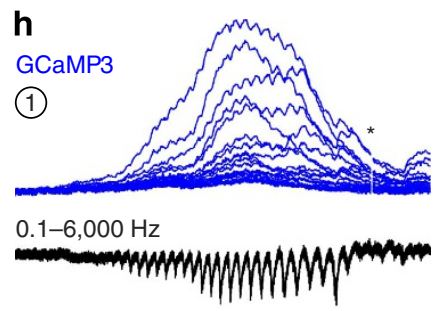

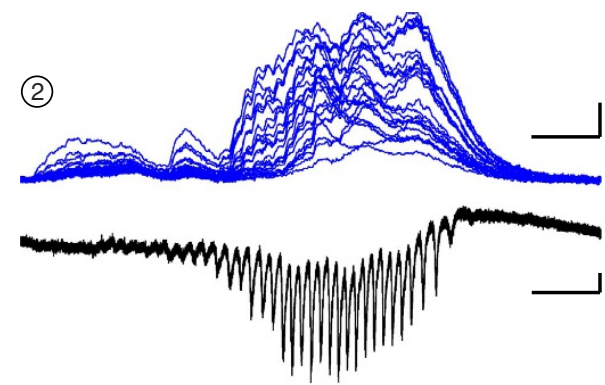

(3)
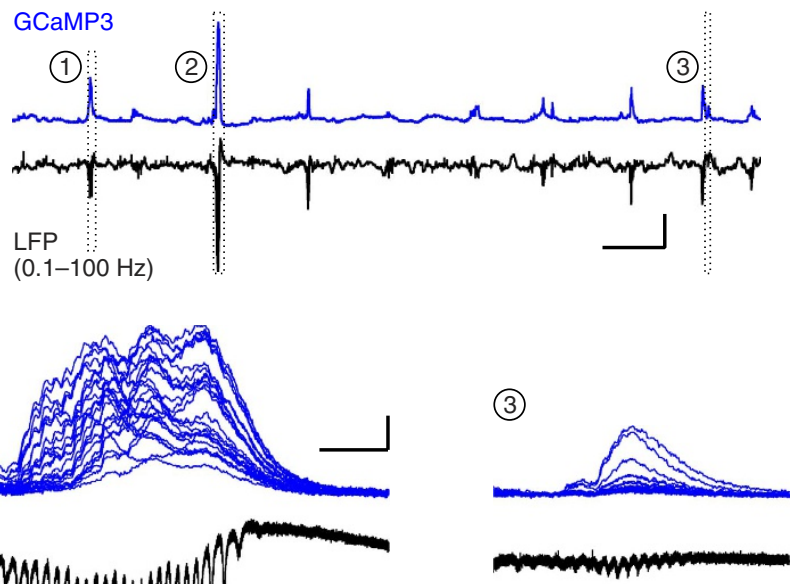

$(0.1-100 \mathrm{~Hz})$
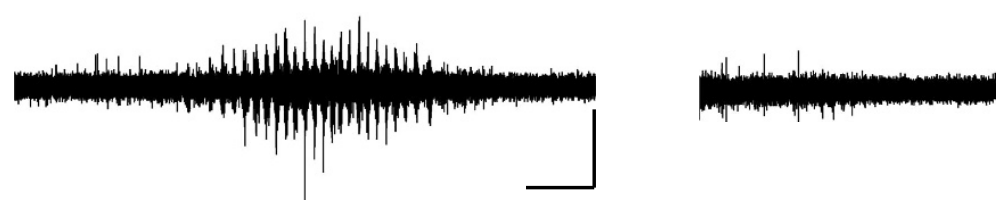

$200-3,000 \mathrm{~Hz}$
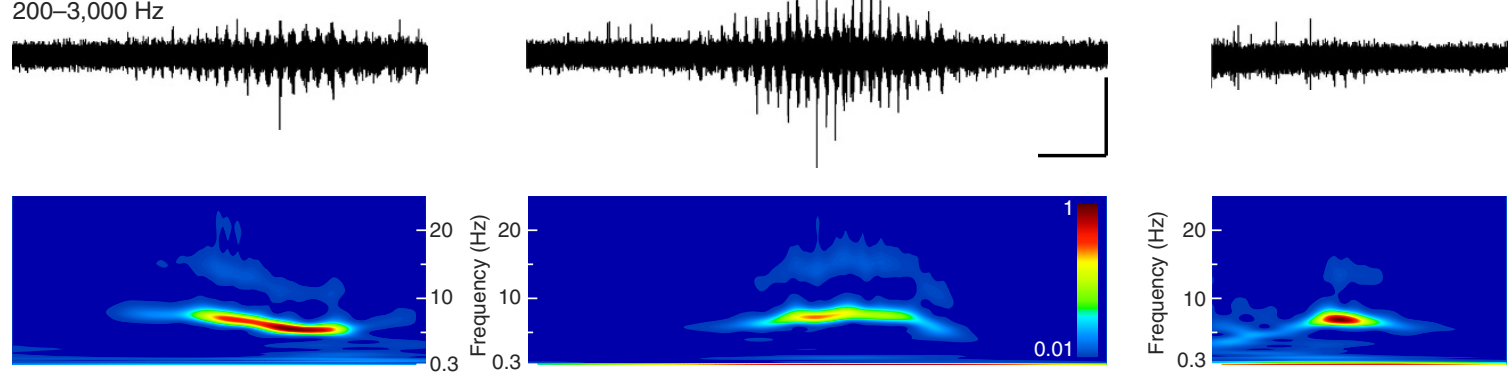

Figure $4 \mathbf{~ C a}^{2}+$ cluster activity in the neonatal occipital neocortex in vivo. (a) Experimental arrangement. (b) GCaMP3 fluorescence overlaid with area plots of four spatially confined cluster events (colour-coded). Binary area plots were calculated from $\Delta F / F_{0}$ sequences (averaged over 10 frames) as maximum intensity projections thresholded at $25 \%$ of the peak amplitude. Scale bar, $200 \mu \mathrm{m}$. (c) Sample traces $\left(\Delta F / F_{0}\right)$ from individual ROls. Colour code refers to clusters in $\mathbf{b}$. Inset corresponds to field of view as shown in $\mathbf{b}$, and indicates positions of ROls from which sample traces were obtained. Note the presence of several spatiotemporally distinct $\mathrm{Ca}^{2+}$ clusters. Scale bars, $0.25 \Delta F / F_{0}, 2 \mathrm{~s}$. (d) Top: Raster plot indicating times of peak of $\mathrm{Ca}^{2+}$ transients from all individual ROls. The time period shown in $\mathbf{c}$ is highlighted in grey. Bottom: time-aligned plot of the fraction of active ROls, obtained by summing peaks over moving windows 10 frames in length. (e) In vivo view of a craniotomy $\left(\sim 1.2 \mathrm{~mm}^{2}\right)$ over the occipital cortex. The field of view during recording (shown in f) is indicated by a dotted rectangle (trans, transverse sinus; sag, superior sagittal sinus; ch, margin of recording chamber). Scale bar, $500 \mu \mathrm{m}$. (f) GCaMP3 fluorescence image after positioning of an extracellular electrode (EC). Scale bar, $200 \mu \mathrm{m}$. (g) Time-aligned sample traces of GCaMP3 fluorescence (average of $25 \mathrm{ROIs}$ shown in $\mathbf{f}$ high-pass filtered at $0.01 \mathrm{~Hz}$ ) and local field potential (LFP, band-pass-filtered at $0.1-100 \mathrm{~Hz}$ ). Scale bars, 0.2 $\Delta F / F_{0}, 200 \mu \mathrm{V}, 50 \mathrm{~s}$. LED synchronization pulses were clipped for clarity. (h) Time-aligned GCaMP3 fluorescence (top, overlaid for 25 ROls shown in $\mathbf{f}$ ), wide-band extracellular signal $(0.1-6,000 \mathrm{~Hz})$, multiunit activity $(200-3,000 \mathrm{~Hz})$ and Morlet wavelet spectrum for the three time intervals indicated in g. Scale bars, $0.2 \Delta F / F_{0}, 100 \mu \mathrm{V}, 1 \mathrm{~s}$. The asterisk in event 1 indicates a single blanked LED synchronization pulse.

activity also involves the upper $\mathrm{CP}(n=5$ mice; Supplementary Fig. $7 \mathrm{a}-\mathrm{d}$ ). To correlate these $\mathrm{Ca}^{2}+$ cluster events to previously reported electrophysiologically defined activity patterns, wideband extracellular recordings $(0.1-6,000 \mathrm{~Hz})$ and wide-field $\mathrm{Ca}^{2+}$ imaging were performed simultaneously $(n=4$ mice). To this end, a low-resistance glass electrode was positioned in the upper $\mathrm{CP}$ under two-photon guidance (Fig. 4e,f). We found that $\mathrm{Ca}^{2+}$ clusters occurring in proximity of the tip of the pipette were paralleled by distinct field potential changes (Fig. $4 \mathrm{~g}$ ). Wavelet- based time-frequency and fast Fourier transform (FFT) analysis revealed that, in the majority of cases, the latter consisted of spindle-shaped oscillations with a dominant frequency in the theta $(4-8 \mathrm{~Hz}$; occasionally and to a lesser extent alpha $(8-13 \mathrm{~Hz}))$ band, typically nested in a delta wave (Fig. 4h). Spindle-like oscillations were usually accompanied by rhythmic multiunit discharges that were phase-locked to the troughs of the spindle oscillation (Fig. $4 \mathrm{~h}$ ). In some cases, spindle-like oscillations were less obvious $(<3$ cycles) or not detectable and the delta 
component was dominant. Interestingly, in several cases, theta oscillations were simultaneously evident in the GCaMP3 signal (see events $\# 1$ and $\# 2$ in Fig. 4h). In summary, the electrophysiological characteristics of $\mathrm{Ca}^{2}+$ clusters agree well with those of previously reported spindle bursts in the visual cortex of neonatal rats ${ }^{50-52}$.

Although the aforementioned measurements were acquired through the intact dura after surgical removal of the overlying bone, virtually identical $\mathrm{Ca}^{2+}$ cluster activity was observed through the intact skull ( $n=3$ mice; Supplementary Fig. $7 \mathrm{e}-\mathrm{k})$. In addition, similar spatiotemporal clusters of CaTs (although with moderately higher frequency and lower cluster size) were also apparent in the absence of $\mathrm{N}_{2} \mathrm{O}$ ( $60 \mathrm{~min}$ after withdrawal of isoflurane, $n=3$ mice; Supplementary Fig. $7 \mathrm{~h}-\mathrm{k})$. In line with previous data, clusters of CaTs were completely suppressed by isoflurane (Supplementary Fig. $7 \mathrm{~h}-\mathrm{k}$, see also refs 42,43 ) and, in addition, entirely action potential-dependent (Supplementary Fig. 7l-o).

GABAergic control of cortical network activity at P3-4. Using wide-field GCaMP3-based $\mathrm{Ca}^{2+}$ imaging, we first examined whether cluster activity required intact $\mathrm{NKCC1}$ and found that bath-applied bumetanide $(50 \mu \mathrm{M})$ did not affect either cluster frequency $\left(f_{\text {cluster }} ; P>0.2, n=5\right.$ mice, paired $t$-test; Fig. $5 c$ and Supplementary Fig. 8a) or cluster size (quantified as the mean number of active ROIs per cluster; $P>0.9$, paired $t$-test; Fig. $5 \mathrm{~d}$ ). In addition, the frequency of spontaneous CaTs per ROI $\left(f_{\mathrm{ROI}}\right)$ remained unaffected $(P>0.15$, paired $t$-test; Fig. 5a,b). Note that the same concentration of bumetanide $(50 \mu \mathrm{M})$ strongly reduced the amplitude of CaTs evoked by exogenous GABA (Fig. 2m-p), confirming that bumetanide is able to penetrate to the ROI. Thus, our data suggest that GABA released synaptically during ongoing network activity does not contribute an essential excitatory drive to cluster activity. We next examined the effects of a use-dependent enhancement of intracortical $\mathrm{GABA}_{\mathrm{A}} \mathrm{R}$-mediated transmission. Bath application of the benzodiazepine diazepam $(70 \mu \mathrm{M})$ strongly inhibited spontaneous network activity as reflected in a reduced $f_{\text {ROI }}(P<0.001, n=6$ mice, paired $t$-test; Fig. 5e,f). This effect was mainly spatial in nature, since diazepam consistently reduced the mean cluster size $(P<0.01$, paired $t$-test; Fig. $5 \mathrm{~h})$, whereas $f_{\text {cluster }}$ was hardly affected $(P>0.1$, paired $t$-test; Fig. $5 \mathrm{~g}$ and Supplementary Fig. $8 \mathrm{~b}$ ). We then investigated the contribution of endogenously released GABA by blocking $\mathrm{GABA}_{\mathrm{A}}$ Rs with gabazine $(40 \mu \mathrm{M})$. This revealed a new type of synchronized and action potential-dependent activity (Supplementary Fig. 7n,o) frequently involving the entire field of view (Fig. 5i). Accordingly, $f_{\text {cluster }}$ was markedly elevated $(P<0.001$, paired $t$-test; Fig. $5 \mathrm{k}$ and Supplementary Fig. $8 \mathrm{c})$ and cluster size strongly increased $(P<0.001$, paired $t$-test; Fig. 5l). As a result, gabazine induced a massive augmentation of $f_{\mathrm{ROI}}$ $(P<0.001$, paired $t$-test; Fig. 5i,j). An inhibitory function of $\mathrm{GABA}_{\mathrm{A}} \mathrm{R}$ activation by endogenous GABA in the upper $\mathrm{CP}$ was further supported by the observation that gabazine enhanced amplitudes of somatic CaTs induced by focal N-Methyl-Daspartate (NMDA) application (Supplementary Fig. 9). We finally asked whether extrasynaptic $\mathrm{GABA}_{\mathrm{A}} \mathrm{Rs}^{53}$ may contribute to the observed gabazine-induced disinhibition of cortical $\mathrm{Ca}^{2}+$ cluster activity. We focussed on $\alpha 5$-subunit-containing $\mathrm{GABA}_{\mathrm{A}} \mathrm{Rs}(\alpha 5$ $\mathrm{GABA}_{\mathrm{A}} \mathrm{Rs}$ ) because of their early developmental expression ${ }^{54}$ and the previously reported involvement in tonic GABAergic currents at the age investigated ${ }^{55}$. Using wide-field $\mathrm{Ca}^{2}+$ imaging, we found that L-655,708 $(1 \mu \mathrm{M})$, an $\alpha 5-\mathrm{GABA}_{\mathrm{A}} \mathrm{R}$-specific inverse agonist, disinhibited network activity as evidenced by an increase in $f_{\mathrm{ROI}}(P<0.05, n=5$ mice, paired $t$-test; Fig. $5 \mathrm{~m}, \mathrm{n})$. This effect was largely spatial in origin because L-655,708 increased the mean cluster size $(P<0.01$, paired $t$-test; Fig. $5 \mathrm{p})$ but did not significantly affect $f_{\text {cluster }}(P>0.4$, paired $t$-test; Fig. 50 and Supplementary Fig. 8d). These data suggest that activation of $\alpha 5-G_{A B A}$ Rs contributes to the spatial confinement of cortical $\mathrm{Ca}^{2}+$ clusters. In summary, we conclude that (at P3-4) GABAergic transmission has an inhibitory function at the network level.

\section{Discussion}

Two independent lines of optical and electrophysiological evidence suggest that GABA acts as a depolarizing neurotransmitter in the developing (P3-4) mouse occipital neocortex. (1) In cell-attached current-clamp recordings, GABA was found to induce depolarization in most neurons examined. (2) When VGCC activation was pharmacologically enhanced using BayK $8644, \mathrm{GABA}_{\mathrm{A}} \mathrm{R}$ activation induced somatic CaTs in the majority of CP cells. Ad (1) Additional experiments in juvenile mice at P25-27 showed that GABA failed to depolarize the majority of more mature layer $2 / 3$ neurons, thereby supporting the concept of a shift in GABA action during brain maturation ${ }^{4}$. At the same age, $\mathrm{GABA}_{\mathrm{A}} \mathrm{R}$-mediated hyperpolarization was detected in only one out of 10 neurons examined (in the presence of a membranepermeable carbonic anhydrase inhibitor). The latter observation strongly suggests that shunting inhibition, rather than hyperpolarization, is the main form of inhibition in the juvenile/adult cortex in vivo (in agreement with previous in vitro data $\left.{ }^{12,21}\right)$. Ad (2) Pharmacological inhibition of NKCC1 strongly reduced the amplitudes of GABA-evoked CaTs, implying an important role for secondary active chloride accumulation in GABAergic transmission in vivo. The latter observation indirectly supports the notion that $\mathrm{GABA}_{\mathrm{A}} \mathrm{R}$ dependent depolarization primarily results from a depolarizing chloride (rather than bicarbonate ${ }^{56}$ ) flux. It should be noted here that drug superfusion of the exposed dura mater (referred to as bath application in the present study) circumvents the bloodbrain barrier. This aspect might be particularly relevant for the NKCC1 blocker bumetanide that poorly penetrates the bloodbrain barrier ${ }^{57}$. In line with the view that NKCC1-dependent chloride accumulation is functional in the intact brain, focal injection of bumetanide was recently reported to reduce the migration velocity of GABAergic interneurons in layer I at P0-3 in vivo ${ }^{58}$. In the presence of BayK 8644 , we found that $55 \%$ and $95 \%$ of cells generated somatic CaTs in response to GABA and muscimol, respectively. Since $\mathrm{GABA}_{\mathrm{B}} \mathrm{Rs}$ do not mediate hyperpolarizing postsynaptic responses in rodent neocortex until the end of the first postnatal week ${ }^{59}$, activation of metabotropic GABA receptors is inapplicable in explaining the difference. Potentially reflecting a differential degree of $\mathrm{GABA}_{\mathrm{A}} \mathrm{R}$ activation (possibly related to the fact that GABA, but not muscimol, represents a substrate for GABA transporters), these data support the conclusion that GABAergic transmission is depolarizing in the majority of immature CP neurons at P3-4. In contrast, a previous study in cerebellar interneurons revealed that $\mathrm{GABA}_{\mathrm{A}} \mathrm{R}$ activation could lead to a rise in $\left[\mathrm{Ca}^{2+}\right]_{\mathrm{i}}$ via an alternative mechanism involving a regulatory volume decrease reaction ${ }^{60}$. Because $\mathrm{GABA}_{\mathrm{A}} \mathrm{R}$-dependent $\mathrm{CaTs}$ in the present study were completely sensitive to the VGCC antagonist $\mathrm{CdCl}_{2}$, this scenario seems unlikely. Theoretically, a transient $\mathrm{GABA}_{\mathrm{A}} \mathrm{R}$ dependent hyperpolarization might activate an excitatory conductance (for example, hyperpolarization-activated $I_{\mathrm{h}}$ or low-voltage-activated $\mathrm{Ca}^{2+}$ channels) that, in turn, could induce a depolarization-dependent rise in $\left[\mathrm{Ca}^{2+}\right]_{i}$ (ref. 61). The latter possibility could be largely ruled out by using cellattached current-clamp recordings that revealed a monophasic time course of GABA-mediated depolarization in most cells examined. 

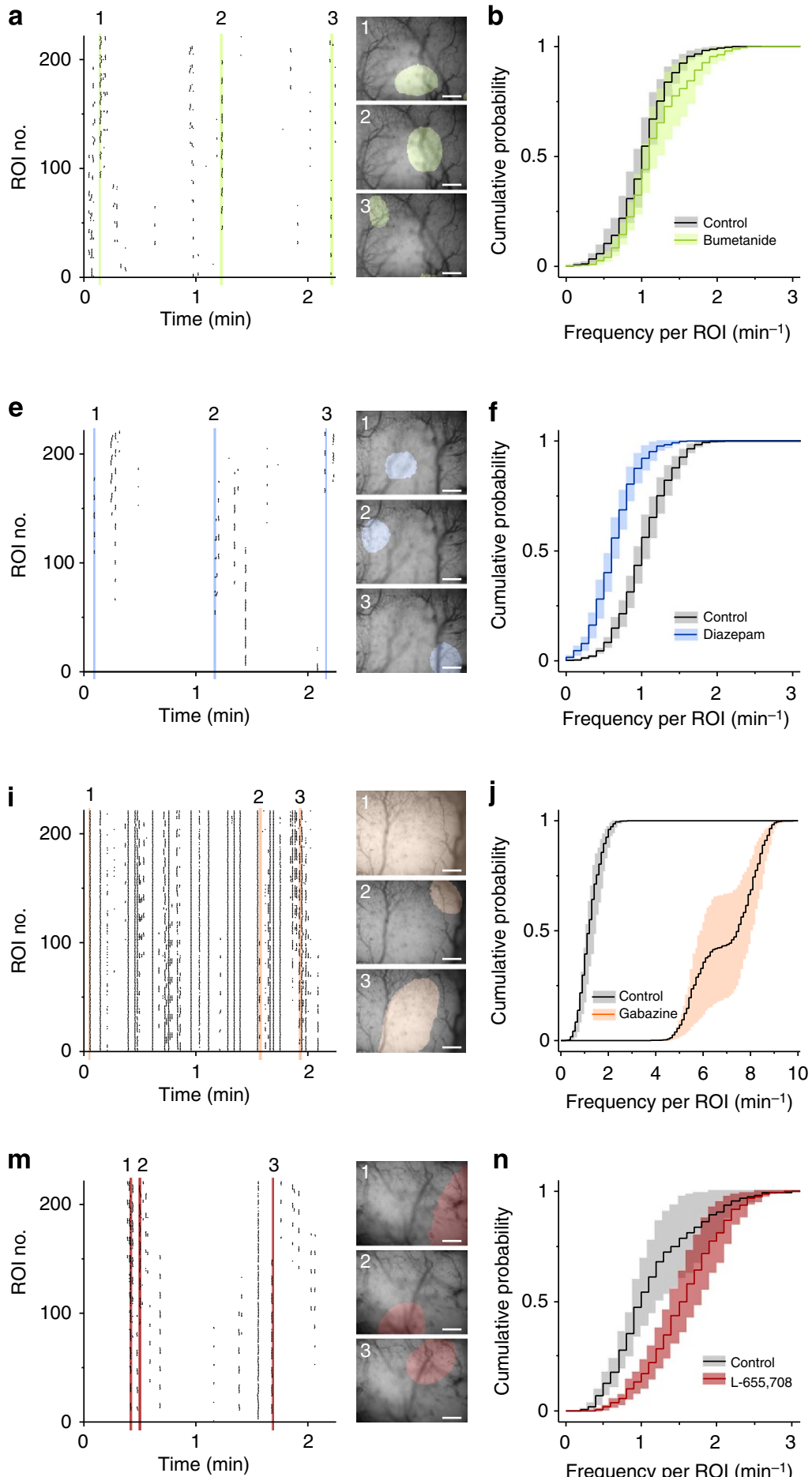
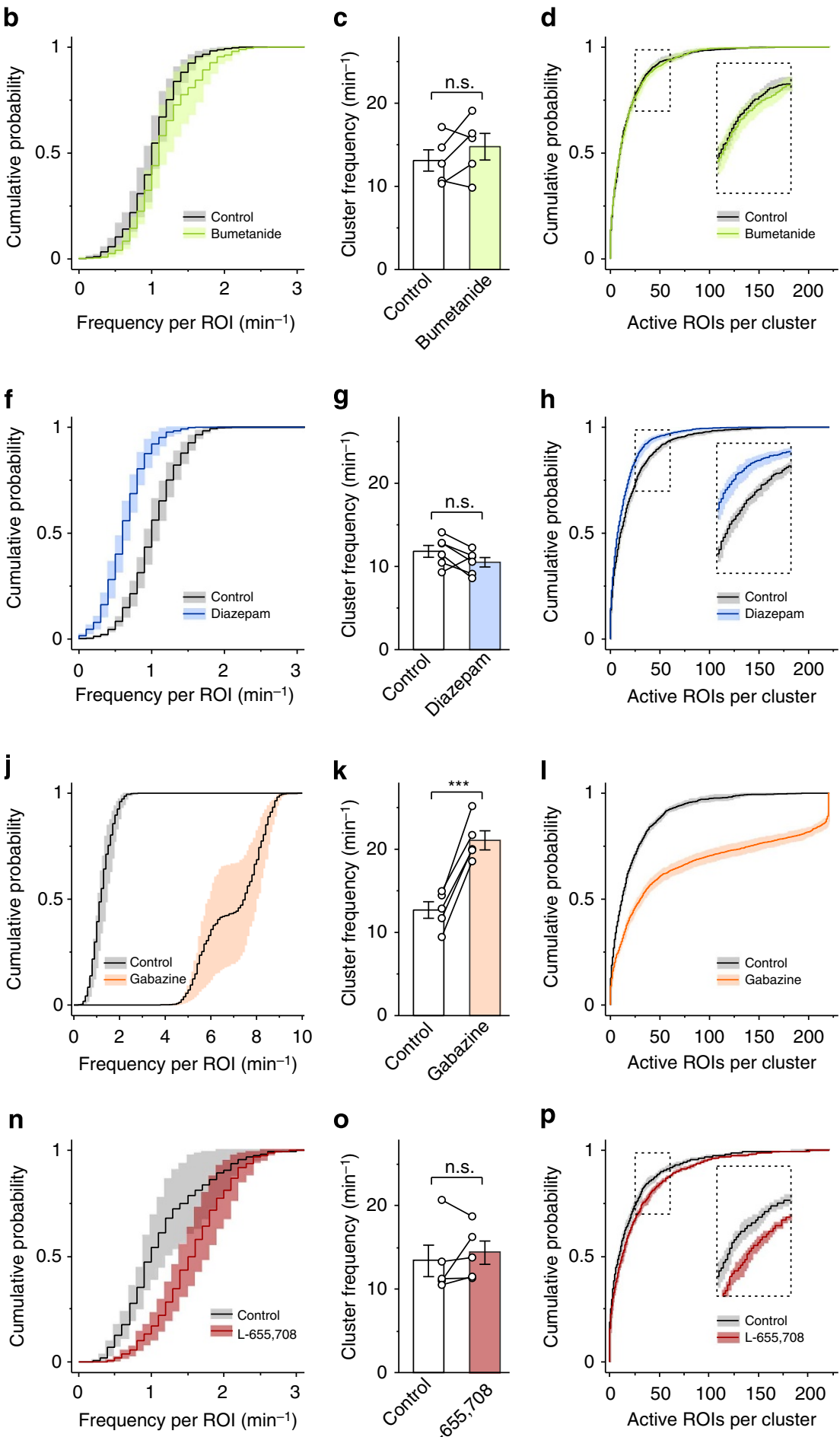

o

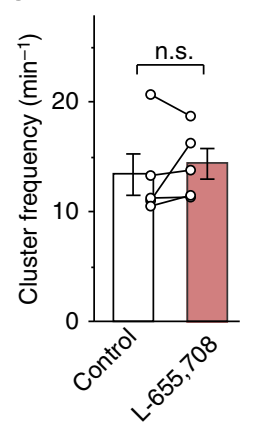

p

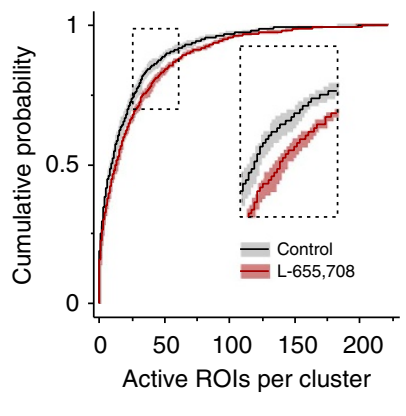

Figure 5 | GABAergic control of neocortical network activity in vivo. (a,e,i,m) Sample raster plots in the presence of bumetanide (a) diazepam (e) gabazine (i) and L-655,708 (m) from four different mice. Insets (right) show GCaMP3 fluorescence overlaid with binary area plots of Ca ${ }^{2}+$ clusters as indicated on the left. Scale bars, $200 \mu \mathrm{m}$. (b,f,j,n) Distributions of the frequency of $\mathrm{Ca}^{2+}$ transients per ROI. The mean (solid line) \pm s.e.m. (shaded area). $(\mathbf{c}, \mathbf{g}, \mathbf{k}, \mathbf{0})$ Cluster frequency (mean \pm s.e.m.) in control versus bumetanide $(P>0.2, n=5$ mice), control versus diazepam $(P>0.1, n=6$ mice $)$, control versus gabazine $(P<0.001, n=5$ mice $)$ and control versus $L-655,708(P>0.4, n=5$ mice; paired $t$-tests). Each pair of symbols represents a single animal. ${ }^{\star \star \star} P<0.001$, n.s., not significant. (d, h, l, p) Distributions of the number of active ROls per $\mathrm{Ca}^{2}{ }^{+}$cluster event. Data presented as the mean (solid line) \pm s.e.m. (shaded area). Insets in $\mathbf{d , h}, \mathbf{p}$ show boxed region at higher magnification.

Under control conditions (that is, in the absence of BayK 8644), both epidural and local (that is, intraparenchymal) puff application of $\mathrm{GABA}_{\mathrm{A}} \mathrm{R}$ agonists mostly failed to induce a distinct rise in $\left[\mathrm{Ca}^{2+}\right]_{i}$ at $\mathrm{P} 3-4$. This finding is in striking contrast to previously reported in vitro data from the $\mathrm{CP}^{5,13,30,41}$, which we corroborated in the present study. The observation cannot be sufficiently explained by desensitization of $\mathrm{GABA}_{\mathrm{A}} \mathrm{Rs}$ and/or VGCCs as a result of slow application kinetics since, in vitro, even 
bath application of GABA (leading to considerably slower [GABA] transients) reliably induced somatic CaTs at the same age ${ }^{5,7}$. In addition, synaptic stimulation in the presence of ionotropic glutamate receptor antagonists did not induce somatic CaTs as well. In agreement with the observed lack of GABAinduced CaTs, both puff application of GABA and afferent GABAergic synaptic stimulation failed to induce action potential firing. These data suggest that $\mathrm{GABA}_{\mathrm{A}} \mathrm{R}$-mediated depolarization in vivo is mostly subthreshold at $\mathrm{P} 3-4$, that is, lacks direct (sensu stricto) excitatory effects. Interestingly, the pharmacological properties of GABA-evoked CaTs in the presence of BayK 8644 were virtually identical to those previously reported from brain slice preparations ${ }^{5,30}$. This supports the notion that differential effects of $\mathrm{GABA}$ on $\left[\mathrm{Ca}^{2+}\right]_{\mathrm{i}}$ in vivo versus in vitro are (in terms of the underlying depolarization) likely quantitative, rather than qualitative, in nature. At present, it is unclear which factors underlie this discrepancy. Certainly, slow active chloride uptake in immature neurons ${ }^{62}$ in conjunction with a higher chloride conductance in vivo versus in vitro, for example, due to synaptic ${ }^{50}$ or extrasynaptic $\mathrm{GABA}_{\mathrm{A}} \mathrm{R}$ activation, represents a potential candidate $^{25}$. Whether traumatic injury might affect results obtained from in vitro preparations is currently highly debated $^{28,44}$. What could be the developmental function of subthreshold-depolarizing GABAergic transmission in the immature cortex? Theoretical considerations and experimental evidence suggest, for instance, that the reversal potential for $\mathrm{GABA}_{\mathrm{A}} \mathrm{R}$-mediated currents (which itself is activity-dependent ${ }^{24}$ ) contributes to the control of spike timing ${ }^{63}$. By modulating spike timing-dependent forms of synaptic plasticity, GABA-mediated depolarization might have developmental effects independent of a gross change in overall activity levels. Interestingly, a recent study proposed that depolarizing GABAergic transmission during early development controls critical-period plasticity in rat visual corte $^{64}$. Collectively, our data reveal that $\mathrm{GABA}_{\mathrm{A}} \mathrm{R}$ activation triggers membrane depolarization in the majority of upper $\mathrm{CP}$ neurons at P3-4 in vivo. It should be stressed that GABAmediated depolarization might even be more pronounced at earlier postnatal stages. In line with this idea, we found that at P1 $\mathrm{GABA}_{\mathrm{A}} \mathrm{R}$ activation induced somatic CaTs in $\sim 9 \%$ of $\mathrm{CP}$ cells in the absence of BayK 8644. Hence, these data could potentially point to an excitatory action of GABA in a subset of neurons at this age. Clearly, further research is required to clarify whether or not this is the case.

Previous electrophysiological and imaging studies identified retinal wave-triggered spindle bursts ${ }^{50}$ or $\mathrm{Ca}^{2+}$ waves $^{43}$ as the dominant network activity pattern in the intact rodent visual cortex. Using simultaneous wide-field $\mathrm{Ca}^{2+}$ imaging and extracellular recording techniques, we show here that network $\mathrm{Ca}^{2+}$ clusters and spindle bursts/delta waves represent homologous events. In line with previous studies from the rat visual corte ${ }^{50,51}$, distinct gamma oscillations were not evident in the present study (as opposed to, for example, somatosensory and motor cortex ${ }^{65}$ ). Our data further revealed that the generation of $\mathrm{Ca}^{2+}$ clusters in the occipital cortex is essentially independent of NKCC1 -in spite of its cellular effects (see above). Computational modelling and experimental studies in vitro have extensively characterized the conditions under which a subthreshold-depolarizing GABAergic conductance may facilitate action potential discharge (excitatory sensu lato) or, alternatively, inhibit neuronal output ${ }^{20-24}$. Although not excluding excitatory sensu lato actions of GABA, our data are compatible with the view that these, if present, are not required to drive spontaneous cortical network activity. Moreover, our data are in agreement with a previous pharmacological characterization of spindle bursts in the somatosensory corte ${ }^{37}$ and suggest that the observed $\mathrm{Ca}^{2}+$ clusters are not the in vivo counterpart of NKCC1-dependent giant depolarizing potentials in vitro, which do depend on depolarizing GABA actions as a promoter of glutamatergic transmission ${ }^{11,12}$. It therefore might be speculated that $\mathrm{Ca}^{2+}$ clusters reported in the present study represent the in vivo analogue of so-called cortical early network oscillations recorded in vitro during the first postnatal week ${ }^{11,13}$ from which, however, $\mathrm{Ca}^{2+}$ clusters appear to differ in spatial extent. Focussing on P3-4, our data obviously do not exclude the possibility that NKCC1 (or even GABAergic depolarization) has a more accentuated role for the generation of in vivo activity patterns during earlier/later developmental periods and/or in other brain regions ${ }^{36}$. Furthermore, we could show that endogenous GABA acting via $\mathrm{GABA}_{\mathrm{A}} \mathrm{Rs}$ exerts a powerful inhibition on cortical $\mathrm{Ca}^{2}+$ clusters by constraining both their frequency of occurrence and their spatial extent. The latter is partially mediated by $\alpha 5-\mathrm{GABA}_{\mathrm{A}} \mathrm{Rs}$, pointing to a role of peri-/ extrasynaptic GABAergic transmission ${ }^{53}$. Whether $\alpha 5-\mathrm{GABA}_{\mathrm{A}} \mathrm{Rs}$ are activated in a phasic (by GABA spillover following synaptic release during $\mathrm{Ca}^{2+}$ cluster activity) and/or tonic (by ambient GABA) manner remains an interesting open question. Our present findings contrast with several (but not all ${ }^{11}$ ) in vitro studies showing that $\mathrm{GABA}_{\mathrm{A}} \mathrm{R}$ blockade in cortical slices partially suppressed large-scale $\mathrm{Ca}^{2+}$ waves ${ }^{13-15}$, but agrees well with previous data on spindle bursts in the intact somatosensory cortex $^{37}$. Disinhibition due to the $\mathrm{GABA}_{\mathrm{A}} \mathrm{R}$ blockade was also observed for focally evoked NMDA receptor-mediated responses in the upper $\mathrm{CP}$. Combining measurements at the single-cell and network level, our data thereby show that, in vivo, depolarizing GABAergic transmission has additional inhibitory functions at the network level, likely via the $\mathrm{GABA}_{\mathrm{A}} \mathrm{R}$-dependent increase in membrane conductance (that is, shunting inhibition). This is in line with both conclusions derived from mathematical modelling and experimental in vitro data ${ }^{22,23}$. It has been hypothesized that, in the neonatal rodent visual cortex, the sequential activation of corresponding retinal and cortical domains is crucial for the proper establishment of retinotopic maps, as previously shown for the optic tectum ${ }^{66}$. Our data support the view that cortical GABAergic transmission is central in maintaining the spatiotemporal specificity of this co-activation.

In summary, by extending previous in vitro investigations, our data identify GABA as a predominantly depolarizing (at the cellular level) and, at the same time, inhibitory (at the network level) neurotransmitter during early (P3-4) cortical development in vivo.

\section{Methods}

Animals. All animal procedures were performed with approval from the local government (registration number: 02-053/11, Thüringer Landesamt für

Verbraucherschutz) and complied with international and European Union norms Experiments were performed on C57BL/6J (two-photon $\mathrm{Ca}^{2+}$ imaging and electrophysiological experiments) and $E m x 1^{I R E S c r e}: G C a M P 3^{L S L}$ (wide-field epifluorescence and two-photon imaging) mice at P3-4 ( $n=92$ mice), except for separate subsets of experiments at P1 $(n=3$ mice) and P25-27 ( $n=8$ mice). Emx $1^{\text {IRESCre }}:$ GCAMP3 ${ }^{L S L}$ mice were obtained by crossing homozygous female Emx $1^{\text {IREScre }}$ mice 48 (The Jackson Laboratory, stock no. 005628) with homozygous male GCaMP3 ${ }^{L S L}$ mice $^{49}$ (Ai38, The Jackson Laboratory, stock no. 014538).

Surgical preparation. For in vivo recordings, animals were deeply anaesthetized with isoflurane (3.5\% for induction, $1-2 \%$ for maintenance) in pure oxygen and the skin overlying the skull locally infiltrated with $2 \%$ lidocaine (s.c.). Scalp and periosteum were removed, and a plastic chamber with a central hole (Ø 2-3 mm) was fixed on the skull using cyanoacrylate glue ${ }^{67,68}$. The recording chamber was tightly connected to the microscope stage and subsequently perfused with ACSF containing (in mM): $125 \mathrm{NaCl}, 4 \mathrm{KCl}, 25 \mathrm{NaHCO}_{3}, 1.25 \mathrm{NaH}_{2} \mathrm{PO}_{4}, 2 \mathrm{CaCl}_{2}, 1$ $\mathrm{MgCl}_{2}$ and 10 glucose $\left(\mathrm{pH}=7.4\right.$ at $35-36^{\circ} \mathrm{C}$; ACSF flow rate $\left.\sim 3 \mathrm{ml} \mathrm{min}^{-1}\right)$. A craniotomy ( $\sim 0.3-0.7 \mathrm{~mm}^{2}$ for single-cell recordings, $\sim 1.0-1.4 \mathrm{~mm}^{2}$ for widefield imaging) was performed above the left occipital cortex using a $27 \mathrm{G}$ needle, except for recordings presented in Supplementary Fig. 7e-h. Care was taken not to damage the underlying dura mater. 
Anaesthesia and animal monitoring during recordings. During in vivo recordings, body temperature was continuously monitored and maintained at close to physiological values $\left(34-37^{\circ} \mathrm{C}\right)$ by means of a heating pad. Spontaneous respiration was monitored using a differential pressure amplifier (Spirometer Pod and PowerLab 4/35, ADInstruments). For wide-field epifluorescence imaging, isoflurane was discontinued after completion of the surgical preparation and gradually substituted with the analgesic-sedative nitrous oxide (up to the fixed final $\mathrm{N}_{2} \mathrm{O} / \mathrm{O}_{2}$ ratio of 3:1). Experiments started $\geq 90 \mathrm{~min}$ after withdrawal of isoflurane. For two-photon $\mathrm{Ca}^{2+}$ imaging, animals were either sedated with $\mathrm{N}_{2} \mathrm{O}$ (as above) or, to reduce the frequency of pup movements, anaesthetized with isoflurane (with or without $\mathrm{N}_{2} \mathrm{O}$ ). Depth of anaesthesia was controlled by adjusting the dose of isoflurane (typically $0.5-1.2 \%$ ) and/or the $\mathrm{N}_{2} \mathrm{O} / \mathrm{O}_{2}$ ratio (up to $3: 1$ ) to maintain a mean respiration rate of $\sim 90-110 \mathrm{~min}^{-1}$. The latter anaesthetic regime was also used for single-cell electrophysiological recordings. For P3-4 mice, body weight before surgery was $2.31 \pm 0.07 \mathrm{~g}(n=60)$, and weight loss during in vivo experiments $(\leq 10 \mathrm{~h})$ amounted to $1.45 \pm 0.14 \%(n=50)$.

Two-photon microscopy. Multicell bolus loading ${ }^{69}$ of cells with the AM-ester of the $\mathrm{Ca}^{2+}$ indicator Oregon Green 488 BAPTA-1 (OGB1, 310-500 $\mu \mathrm{M}$ ) was performed by pressure ejection (for $1-2 \mathrm{~min}$ at $40-50 \mathrm{kPa}$ ) using a patch pipette (3-7 M $\Omega, \sim 150-300 \mu \mathrm{m}$ below pia). To allow for de-esterification, recordings were performed at $>1 \mathrm{~h}$ post-OGB1 AM injection. Imaging was performed using a Movable Objective Microscope (Sutter Instrument) controlled by the software MPScope 2.0 and custom-made software written in LabView (National Instruments). Fluorescence excitation at $800-830 \mathrm{~nm}$ (OGB1) or $920 \mathrm{~nm}$ (GCaMP3) was provided by a tunable Ti:Sapphire laser (Chameleon Ultra II, Coherent) using a $\times 20 / 1.0$ NA water immersion objective (Olympus). Emission light was separated from excitation light using a 670-nm dichroic mirror $(670$ DCXXR, Chroma Technology), filtered at $535 / 50 \mathrm{~nm}$ and detected by a photomultiplier tube (H10770PA-40, Hamamatsu). Images were typically acquired at a frame rate of $11.6 \mathrm{~Hz}(256 \times 256$ pixels $)$ or $3.4 \mathrm{~Hz}(512 \times 512$ pixels $)$. Recordings were performed in the upper CP (usually $<150 \mu \mathrm{m}$ below pia). For analysis, fluorescence signals from cell somata (manually outlined in an average image of the pre-stimulus period) were, if possible, corrected for background fluorescence (calculated from the lumen of a cross-sectioned blood vessel) and expressed as relative changes from pre-stimulus levels $\left(\Delta F / F_{0}\right)$. Normalized rise slopes for glutamate-induced responses were calculated as follows: first, a two-term Boltzmann function was fitted to the $\Delta F / F_{0}$ time series. Second, the maximum slope during the rising phase of the responses was determined from the fit and, finally, normalized to the amplitude of the response.

\section{Electrophysiological recordings. Electrophysiological signals were acquired} using an Axopatch 200B (patch-clamp) or Multiclamp 700B (patch-clamp and extracellular recordings) amplifier, a 16-bit AD/DA board (Digidata 1440A) and pClamp 10.2 (Molecular Devices). Signals were either low-pass-filtered at $2 \mathrm{kHz}$ and sampled at $20 \mathrm{kHz}$ in patch-clamp studies or band-pass-filtered at $0.1-6,000 \mathrm{~Hz}$ and sampled at $100 \mathrm{kHz}$ in extracellular recordings. A shadowpatching approach was used to visually target recordings to the upper $\mathrm{CP}$. To this end, pipette solutions were supplemented with Alexa Fluor $488(100$ or $500 \mu \mathrm{M})$ and visualized by two-photon excitation at $920-930 \mathrm{~nm}$. All cells included in the analysis were identified as neurons on the basis of (I) their ability to generate action potentials/currents (in whole-cell/cell-attached mode) either spontaneously or evoked (by voltage jumps or puff-applied glutamate) or (II) in some cases (at $\mathrm{P} 25-27)$ by the presence of postsynaptic currents in the whole-cell mode.

To evaluate the polarity of GABA-induced membrane potential changes, tightseal cell-attached current-clamp recordings were performed $(I=0$ mode of the amplifier $^{30,40,70}$. Recording pipettes (3-7 M $\Omega$ ) were filled with one of the following solutions (in $\mathrm{mM}$ ): (1) $140 \mathrm{~K}^{+}$gluconate, $10 \mathrm{HEPES}, 11 \mathrm{EGTA}, 1 \mathrm{CaCl}_{2}$ and 2 $\mathrm{MgCl}_{2}\left(\mathrm{pH}\right.$ 7.25) or (2) $135 \mathrm{~K}^{+}$gluconate, $5 \mathrm{KCl}, 10 \mathrm{HEPES}, 11 \mathrm{EGTA}, 1 \mathrm{CaCl}_{2}$ and $2 \mathrm{MgCl}_{2}$ (pH 7.25). Total resistance measured in the cell-attached mode was $6.5 \pm 0.31 \mathrm{G} \Omega(n=15)$ at P3-4 and $6.3 \pm 0.46 \mathrm{G} \Omega(n=16)$ at $\mathrm{P} 25-27$.

To quantify agonist-induced changes in membrane resistance, whole-cell voltage-clamp recordings were performed at a holding potential of $-70 \mathrm{mV}$ (not corrected for liquid junction potentials; pipette solutions as above). Series resistance $\left(R_{\mathrm{s}}\right)$ was estimated from the peak current in response to hyperpolarizing $(-10 \mathrm{mV}, 50 \mathrm{~ms})$ voltage steps, and membrane resistance $\left(R_{\mathrm{m}}\right)$ from the respective steady-state current $\left(I_{\mathrm{ss}}\right)$ assuming that $R_{\mathrm{m}}$ and $R_{\mathrm{s}}$ additively contribute to $I_{\mathrm{ss}}$. In this set of experiments, $R_{\mathrm{s}}$ amounted to $42 \pm 1.9 \mathrm{M} \Omega$, reflecting an $R_{\mathrm{s}} / R_{\mathrm{m}}$ ratio of $6.8 \pm 1.0 \%(n=9)$

For measurements of agonist-induced action currents, loose-patch (seal resistance $<100 \mathrm{M} \Omega$ ) or tight-seal $(>1 \mathrm{G} \Omega$ ) cell-attached recordings were performed in the voltage-clamp mode using glass pipettes filled with the following solution (in $\mathrm{mM}$ ): $150 \mathrm{NaCl}, 4 \mathrm{KCl}$ and 10 HEPES (pH 7.4). Holding current was manually zeroed before each experiment.

Extracellular recordings were performed using glass pipettes beveled to a resistance of 200-500 $\mathrm{k} \Omega$. Recording pipettes were positioned in the upper $\mathrm{CP}$ under two-photon guidance. For synchronization with wide-field $\mathrm{Ca}^{2+}$ imaging, a light-emitting diode was used to deliver 2-ms light pulses at intervals of $1 \mathrm{~min}$.
Electrical stimulation. For electrical stimulation of afferent fibres, a low-resistance (200-500 k $\Omega$ ) glass electrode was positioned in the upper CP under two-photon guidance. Each trial of stimulation consisted of 25 pulses $(40-100 \mathrm{~V}, 200 \mu \mathrm{s})$ delivered at $50 \mathrm{~Hz}$ using an isolated pulse stimulator (Model 2100, A-M Systems) In two-photon $\mathrm{Ca}^{2+}$ imaging experiments, cells were classified as responsive if, within an interval of $2.15 \mathrm{~s}$ ( 25 frames) after the start of stimulation, $\Delta F / F_{0}$ exceeded a threshold of three times the s.d. of the baseline noise for $\geq 3$ frames (this was separately carried out for each single trial and the averaged $\Delta F / F_{0}$ time series). For patch-clamp recordings, we first performed multicell bolus loading with OGB1 to identify the responsive region (in standard ACSF) within which cellattached recordings were subsequently conducted. Synaptically evoked action currents were differentiated from antidromically induced responses on the basis of their latency $(>2 \mathrm{~ms})$.

Wide-field epifluorescence microscopy. One-photon excitation of the genetically encoded $\mathrm{Ca}^{2+}$ indicator GCaMP3 was provided by a xenon arc lamp (Lambda LS, Sutter Instrument) coupled via a liquid light guide to the epifluorescence port of a Movable Objective Microscope (Sutter Instrument) and filtered at $472 / 30 \mathrm{~nm}$. Emission was separated from excitation light at $495 \mathrm{~nm}$ and long-pass-filtered at $496 \mathrm{~nm}$ (AHF Analysentechnik). Images were acquired using a $\times 10 / 0.3$ NA water immersion objective (Zeiss) and a 12-bit Rolera-XR camera (QImaging) operated by the software Streampix 5 (NorPix). Frame rate was set to $74.14 \mathrm{~Hz}$ using $4 \times 4$ hardware binning $(170 \times 130$ pixels; field of view: $1,134 \times 867 \mu \mathrm{m})$. Recording time per condition typically amounted to $18.0 \mathrm{~min}$ (range: 13.2-22.4 min). For analysis, periods of movement artefacts were first identified by visual inspection of raw image sequences and discarded since they frequently resulted in obviously false-positive detection results. Image sequences were then binned $(10 \times 10)$, giving rise to a regular grid of $17 \times 13=221$ ROIs (ROI dimensions: $66.7 \times 66.7 \mu \mathrm{m}$ ). Next, intensity-versus-time plots were extracted using ImageJ 1.47 (http://rsbweb.nih.gov/ij/). Unbiased peak detection of spontaneous CaTs was performed using a template-matching algorithm implemented in pClamp 10.2. 'Clusters' of CaT peaks were defined on a temporal basis as follows. Extracted peak times were binned (bin width $=5$ frames, $\sim 67.4 \mathrm{~ms}$ ) and neighbouring non-empty bins (that is, bins with $\geq 1$ peak) were considered to belong to a common temporal cluster if they were separated by less than two empty bins. The mean frequencies of CaTs per ROI as well as the mean cluster frequencies were calculated as the ratio of number of events per corrected recording time (that is, total recording time minus cumulative movement artefact-associated recording time).

Drug application. In vivo epidural puff application of agonists $(100 \mathrm{mM}$ glutamate, $100 \mathrm{mM}$ GABA, $5 \mathrm{mM}$ muscimol and $5 \mathrm{mM}$ baclofen) or ACSF at a nominal pressure of $69 \mathrm{kPa}$ (Toohey Spritzer) was performed via a patch pipette (typically 3-6 M $\Omega$ ) positioned in close proximity to the intact dura. Substances for application were dissolved in extracellular solution of the respective control condition. In electrophysiological experiments, a 'standard' GABA or glutamate puff of constant duration ( $5 \mathrm{~s}$ ) was used. In these experiments, the application pipette additionally included the red fluorescent dye Alexa Fluor $594(100 \mu \mathrm{M}$; excited at $830 \mathrm{~nm}$ ). Trials were accepted for analysis if application was associated with a distinct increase in fluorescence in the immediate vicinity of the recorded neuron, but otherwise discarded. In two-photon $\mathrm{Ca}^{2+}$ imaging experiments involving epidural applications, fluorescent dyes were omitted from application solutions. Instead, the following procedure was applied: (I) epidural puff application of glutamate leads to spatially confined cell activation because of limited agonist diffusion distance. Therefore, we used puff application of glutamate to validate proper pipette positioning. Within the activation volume, almost all cells ( $>95 \%)$ did respond to glutamate. (II) The duration of the glutamate puff was adjusted such that the mean $\Delta F / F_{0}$ was in the order of 1.0-1.5. This duration was defined as $t_{\text {short }}$ (for experiments in Fig. $2 \mathrm{~b}-\mathrm{d}, t_{\text {short }}$ ranged from 0.3 to $2.0 \mathrm{~s}$ ). Setting the application time to $67 \%$ of $t_{\text {short }}$ reduced the amplitude of full-field responses to $59.0 \pm 3.4 \%$ ( $n=4$ mice). (III) The glutamate-containing pipette was replaced by a second pipette that contained a GABA receptor agonist, and the experiment was repeated (again using $\left.t_{\text {short }}\right)$. For experiments depicted in Fig. 2e-p, a prolonged GABA application time was used according to the definition: $t_{\text {long }}=5 \times t_{\text {short }}$. An analogous procedure was applied during in vitro $\mathrm{Ca}^{2+}$ imaging experiments

(Supplementary Fig. 3). To reduce differences in effective concentrations, agonist concentrations were reduced ( $1 \mathrm{mM}$ glutamate, $1 \mathrm{mM}$ GABA) so as to compensate for the lack of diffusional barriers in the slice preparation that are present in vivo (for example, dura mater). Moreover, application times $\left(t_{\text {short }}\right)$ were adjusted such that amplitudes of glutamate-induced CaTs in vitro were similar to those measured in vivo. For in vivo experiments involving local pressure application of GABA $(10 \mathrm{mM})$ or glutamate $(10 \mathrm{mM})$, pipettes (typically $10-15 \mathrm{M} \Omega$ ) were supplemented with Alexa Fluor $594(20 \mu \mathrm{M})$ to verify solution outflow. Local puff application (30 or $40 \mathrm{~ms}$ ) resulted in a circumscribed mechanical artefact close to the pipette tip ( area $=1.2 \pm 0.1 \times 10^{3} \mu \mathrm{m}^{2}, n=18$ trials). Cells located within this area were excluded from further analysis. A cell was considered responsive to glutamate (in vivo and in vitro) if glutamate-induced $\Delta F / F_{0} \geq 0.2$. Under control conditions, responsiveness to GABA was defined on the basis of a threshold criterion derived as follows: the mean standard deviation of the baseline noise (s.d.) was 0.05 for both $t_{\text {short }}$ and $t_{\text {long }}$ at P1. At P3-4, s.d. amounted to 0.06 for $t_{\text {short }}$ and 0.07 for $t_{\text {long }}$. 
Cells were classified as responsive to GABA if (I) $\Delta F / F_{0}>0.08$ (set constant for all cells analysed) and, to minimize the number of false positives, (II) $\Delta F / F_{0}>3 \times$ s.d. (here s.d. refers to the specific cell analysed).

Preparation of acute brain slices. Animals were decapitated under deep isoflurane anaesthesia. The brain was removed quickly and transferred into ice-cold saline containing (in mM): $125 \mathrm{NaCl}, 4 \mathrm{KCl}, 10$ glucose, $1.25 \mathrm{NaH}_{2} \mathrm{PO}_{4}, 25$ $\mathrm{NaHCO}_{3}, 0.5 \mathrm{CaCl}_{2}$ and $2.5 \mathrm{MgCl}_{2}$, bubbled with $5 \% \mathrm{CO}_{2} / 95 \% \mathrm{O}_{2}$ (pH 7.4). Coronal slices $(350 \mu \mathrm{m})$ comprising the occipital cortex were cut on a vibratome (VT1200 S, Leica) and stored for at least $1 \mathrm{~h}$ before use at room temperature in ACSF. For recordings, slices were placed into a submerged-type recording chamber (ACSF flow rate $\sim 3 \mathrm{ml} \mathrm{min}^{-1}$ ) on the stage of a Movable Objective Microscope (see above). All experiments were performed at $35-36^{\circ} \mathrm{C}$.

Chemicals. Chemicals were obtained from Sigma (GABA, glutamate sodium salt, muscimol, APV, bumetanide, cadmium chloride, 6,7-dinitroquinoxaline2,3(1H,4H)-dione (DNQX), EZA, L-655,708, NMDA, picrotoxin, gabazine), Tocris [(R)-baclofen, (S)-(-)-BayK 8644] and Biotrend (TTX). Diazepam was obtained from Krewel Meuselbach (Valocordin) and Caesar \& Loretz.

Statistics. Statistical analyses were performed using OriginPro 8/9, Microsoft Excel 2003/2010 and SPSS Statistics 19. All data are reported as mean \pm s.e.m. Unless otherwise stated, the statistical parameter $n$ refers to the number of animals in $\mathrm{Ca}^{2+}$ imaging experiments or to the number of cells in electrophysiological recordings. The Shapiro-Wilk test was used to test for the normality of data. Parametric testing procedures were applied for normally distributed data; otherwise nonparametric tests were used. $P$ values (two-tailed tests) $<0.05$ were considered statistically significant.

\section{References}

1. Krnjevic, K. \& Phillis, J. W. Iontophoretic studies of neurones in the mammalian cerebral cortex. J. Physiol. 165, 274-304 (1963).

2. Curtis, D. R., Duggan, A. W., Felix, D. \& Johnston, G. A. GABA, bicuculline and central inhibition. Nature 226, 1222-1224 (1970).

3. Ben-Ari, Y., Cherubini, E., Corradetti, R. \& Gaiarsa, J. L. Giant synaptic potentials in immature rat CA3 hippocampal neurones. J. Physiol. 416, 303-325 (1989).

4. Ben-Ari, Y., Khalilov, I., Kahle, K. T. \& Cherubini, E. The GABA excitatory/ inhibitory shift in brain maturation and neurological disorders. Neuroscientist 18, 467-486 (2012).

5. Yamada, J. et al. Cl- uptake promoting depolarizing GABA actions in immature rat neocortical neurones is mediated by NKCC1. J. Physiol. 557, 829-841 (2004).

6. Brumback, A. C. \& Staley, K. J. Thermodynamic regulation of NKCC1mediated Cl- cotransport underlies plasticity of GABA(A) signaling in neonatal neurons. J. Neurosci. 28, 1301-1312 (2008).

7. Pfeffer, C. K. et al. NKCC1-dependent GABAergic excitation drives synaptic network maturation during early hippocampal development. J. Neurosci. 29, 3419-3430 (2009).

8. Rivera, C. et al. The $\mathrm{K}+/ \mathrm{Cl}$ - co-transporter KCC2 renders GABA hyperpolarizing during neuronal maturation. Nature 397, 251-255 (1999).

9. Hübner, C. A. \& Holthoff, K. Anion transport and GABA signaling. Front. Cell Neurosci. 7, 177 (2013).

10. Kaila, K., Price, T. J., Payne, J. A., Puskarjov, M. \& Voipio, J. Cation-chloride cotransporters in neuronal development, plasticity and disease. Nat. Rev. Neurosci. 15, 637-654 (2014).

11. Allene, C. et al. Sequential generation of two distinct synapse-driven network patterns in developing neocortex. J. Neurosci. 28, 12851-12863 (2008).

12. Rheims, S. et al. Excitatory GABA in rodent developing neocortex in vitro. J. Neurophysiol. 100, 609-619 (2008).

13. Garaschuk, O., Linn, J., Eilers, J. \& Konnerth, A. Large-scale oscillatory calcium waves in the immature cortex. Nat. Neurosci. 3, 452-459 (2000).

14. Conhaim, J. et al. Bimodal septal and cortical triggering and complex propagation patterns of spontaneous waves of activity in the developing mouse cerebral cortex. Dev. Neurobiol. 70, 679-692 (2010).

15. Conhaim, J. et al. Developmental changes in propagation patterns and transmitter dependence of waves of spontaneous activity in the mouse cerebral cortex. J. Physiol. 589, 2529-2541 (2011).

16. Tyzio, R. et al. The establishment of GABAergic and glutamatergic synapses on CA1 pyramidal neurons is sequential and correlates with the development of the apical dendrite. J. Neurosci. 19, 10372-10382 (1999).

17. Represa, A. \& Ben-Ari, Y. Trophic actions of GABA on neuronal development. Trends Neurosci. 28, 278-283 (2005).

18. Wang, D. D. \& Kriegstein, A. R. GABA regulates excitatory synapse formation in the neocortex via NMDA receptor activation. J. Neurosci. 28, 5547-5558 (2008).
19. Young, S. Z. et al. NKCC1 knockdown decreases neuron production through GABAA-regulated neural progenitor proliferation and delays dendrite development. J. Neurosci. 32, 13630-13638 (2012).

20. Kolbaev, S. N., Achilles, K., Luhmann, H. J. \& Kilb, W. Effect of depolarizing GABAA-mediated membrane responses on the excitability of Cajal-Retzius cells in the immature rat neocortex. J. Neurophysiol. 106, 2034-2044 (2011).

21. Gulledge, A. T. \& Stuart, G. J. Excitatory actions of GABA in the cortex. Neuron 37, 299-309 (2003).

22. Morita, K., Tsumoto, K. \& Aihara, K. Bidirectional modulation of neuronal responses by depolarizing GABAergic inputs. Biophys. J. 90, 1925-1938 (2006).

23. Jean-Xavier, C., Mentis, G. Z., O’Donovan, M. J., Cattaert, D. \& Vinay, L. Dual personality of GABA/glycine-mediated depolarizations in immature spinal cord. Proc. Natl Acad. Sci. USA 104, 11477-11482 (2007).

24. Kolbaev, S. N., Luhmann, H. J. \& Kilb, W. Activity-dependent scaling of GABAergic excitation by dynamic $\mathrm{Cl}(-)$ changes in Cajal-Retzius cells. Pflugers Arch. 461, 557-565 (2011).

25. Marchetti, C., Tabak, J., Chub, N., O’Donovan, M. J. \& Rinzel, J. Modeling spontaneous activity in the developing spinal cord using activity-dependent variations of intracellular chloride. J. Neurosci. 25, 3601-3612 (2005).

26. Rheims, S. et al. GABA action in immature neocortical neurons directly depends on the availability of ketone bodies. J. Neurochem. 110, 1330-1338 (2009).

27. Holmgren, C. D. et al. Energy substrate availability as a determinant of neuronal resting potential, GABA signaling and spontaneous network activity in the neonatal cortex in vitro. J. Neurochem. 112, 900-912 (2010).

28. Dzhala, V., Valeeva, G., Glykys, J., Khazipov, R. \& Staley, K. Traumatic alterations in GABA signaling disrupt hippocampal network activity in the developing brain. J. Neurosci. 32, 4017-4031 (2012).

29. Ruusuvuori, E., Kirilkin, I., Pandya, N. \& Kaila, K. Spontaneous network events driven by depolarizing GABA action in neonatal hippocampal slices are not attributable to deficient mitochondrial energy metabolism. J. Neurosci. 30, 15638-15642 (2010).

30. Kirmse, K., Witte, O. W. \& Holthoff, K. GABA depolarizes immature neocortical neurons in the presence of the ketone body $\beta$-hydroxybutyrate. J. Neurosci. 30, 16002-16007 (2010).

31. Tyzio, R. et al. Depolarizing actions of GABA in immature neurons depend neither on ketone bodies nor on pyruvate. J. Neurosci. 31, 34-45 (2011).

32. Khakhalin, A. S. \& Aizenman, C. D. GABAergic transmission and chloride equilibrium potential are not modulated by pyruvate in the developing optic tectum of Xenopus laevis tadpoles. PLoS ONE 7, e34446 (2012).

33. Valeeva, G., Valiullina, F. \& Khazipov, R. Excitatory actions of GABA in the intact neonatal rodent hippocampus in vitro. Front. Cell Neurosci. 7, 20 (2013)

34. Brustein, E., Marandi, N., Kovalchuk, Y., Drapeau, P. \& Konnerth, A. "In vivo" monitoring of neuronal network activity in zebrafish by two-photon $\mathrm{Ca}(2+)$ imaging. Pflugers Arch. 446, 766-773 (2003).

35. Zhang, R. W., Wei, H. P., Xia, Y. M. \& Du, J. L. Development of light response and GABAergic excitation-to-inhibition switch in zebrafish retinal ganglion cells. J. Physiol. 588, 2557-2569 (2010).

36. Sipila, S. T., Schuchmann, S., Voipio, J., Yamada, J. \& Kaila, K. The cationchloride cotransporter NKCC1 promotes sharp waves in the neonatal rat hippocampus. J. Physiol. 573, 765-773 (2006).

37. Minlebaev, M., Ben-Ari, Y. \& Khazipov, R. Network mechanisms of spindleburst oscillations in the neonatal rat barrel cortex in vivo. J. Neurophysiol. 97, 692-700 (2007).

38. Minlebaev, M., Colonnese, M., Tsintsadze, T., Sirota, A. \& Khazipov, R. Early gamma oscillations synchronize developing thalamus and cortex. Science 334, 226-229 (2011).

39. Baram, T. Z. \& Snead, 3rd O. C. Bicuculline induced seizures in infant rats: ontogeny of behavioral and electrocortical phenomena. Brain Res. Dev. Brain Res. 57, 291-295 (1990).

40. Perkins, K. L. Cell-attached voltage-clamp and current-clamp recording and stimulation techniques in brain slices. J. Neurosci. Methods 154, 1-18 (2006).

41. Owens, D. F., Boyce, L. H., Davis, M. B. \& Kriegstein, A. R. Excitatory GABA responses in embryonic and neonatal cortical slices demonstrated by gramicidin perforated-patch recordings and calcium imaging. J. Neurosci. 16, 6414-6423 (1996).

42. Adelsberger, H., Garaschuk, O. \& Konnerth, A. Cortical calcium waves in resting newborn mice. Nat. Neurosci. 8, 988-990 (2005).

43. Ackman, J. B., Burbridge, T. J. \& Crair, M. C. Retinal waves coordinate patterned activity throughout the developing visual system. Nature 490 , 219-225 (2012).

44. Ben-Ari, Y. et al. Refuting the challenges of the developmental shift of polarity of GABA actions: GABA more exciting than ever! Front. Cell Neurosci. 6, 35 (2012).

45. Hess, P., Lansman, J. B. \& Tsien, R. W. Different modes of Ca channel gating behaviour favoured by dihydropyridine Ca agonists and antagonists. Nature 311, 538-544 (1984). 
46. Darcy, D. P. \& Isaacson, J. S. L-type calcium channels govern calcium signaling in migrating newborn neurons in the postnatal olfactory bulb. J. Neurosci. 29, 2510-2518 (2009).

47. Kerr, J. N., Greenberg, D. \& Helmchen, F. Imaging input and output of neocortical networks in vivo. Proc. Natl Acad. Sci. USA 102, 14063-14068 (2005).

48. Gorski, J. A. et al. Cortical excitatory neurons and glia, but not GABAergic neurons, are produced in the Emxl-expressing lineage. J. Neurosci. 22, 6309-6314 (2002).

49. Zariwala, H. A. et al. A Cre-dependent GCaMP3 reporter mouse for neuronal imaging in vivo. J. Neurosci. 32, 3131-3141 (2012).

50. Hanganu, I. L., Ben-Ari, Y. \& Khazipov, R. Retinal waves trigger spindle bursts in the neonatal rat visual cortex. J. Neurosci. 26, 6728-6736 (2006).

51. Hanganu, I. L., Staiger, J. F., Ben-Ari, Y. \& Khazipov, R. Cholinergic modulation of spindle bursts in the neonatal rat visual cortex in vivo. J. Neurosci. 27, 5694-5705 (2007).

52. Colonnese, M. T. et al. A conserved switch in sensory processing prepares developing neocortex for vision. Neuron 67, 480-498 (2010).

53. Brickley, S. G. \& Mody, I. Extrasynaptic GABA(A) receptors: their function in the CNS and implications for disease. Neuron 73, 23-34 (2012).

54 . Heinen, K. et al. GABAA receptor maturation in relation to eye opening in the rat visual cortex. Neuroscience 124, 161-171 (2004).

55. Sebe, J. Y., Looke-Stewart, E. C., Estrada, R. C. \& Baraban, S. C. Robust tonic GABA currents can inhibit cell firing in mouse newborn neocortical pyramidal cells. Eur. J. Neurosci. 32, 1310-1318 (2010).

56. Kaila, K., Voipio, J., Paalasmaa, P., Pasternack, M. \& Deisz, R. A. The role of bicarbonate in GABAA receptor-mediated IPSPs of rat neocortical neurones. J. Physiol. 464, 273-289 (1993).

57. Loscher, W., Puskarjov, M. \& Kaila, K. Cation-chloride cotransporters NKCC1 and KCC2 as potential targets for novel antiepileptic and antiepileptogenic treatments. Neuropharmacology 69, 62-74 (2013).

58. Inada, H. et al. GABA regulates the multidirectional tangential migration of GABAergic interneurons in living neonatal mice. PLoS ONE 6, e27048 (2011).

59. Bony, G. et al. Non-hyperpolarizing GABAB receptor activation regulates neuronal migration and neurite growth and specification by cAMP/LKB1. Nat. Commun. 4, 1800 (2013).

60. Chavas, J., Forero, M. E., Collin, T., Llano, I. \& Marty, A. Osmotic tension as a possible link between $\mathrm{GABA}(\mathrm{A})$ receptor activation and intracellular calcium elevation. Neuron 44, 701-713 (2004).

61. Aizenman, C. D. \& Linden, D. J. Regulation of the rebound depolarization and spontaneous firing patterns of deep nuclear neurons in slices of rat cerebellum. J. Neurophysiol. 82, 1697-1709 (1999).

62. Achilles, K. et al. Kinetic properties of $\mathrm{Cl}$ uptake mediated by $\mathrm{Na}+$-dependent $\mathrm{K}+-2 \mathrm{Cl}$ cotransport in immature rat neocortical neurons. J. Neurosci. 27, 8616-8627 (2007).

63. Valeeva, G. et al. Temporal coding at the immature depolarizing GABAergic synapse. Front. Cell Neurosci. 4 (2010).

64. Deidda, G. et al. Early depolarizing GABA controls critical-period plasticity in the rat visual cortex. Nat. Neurosci. 18, 87-96 (2015).
65. An, S., Kilb, W. \& Luhmann, H. J. Sensory-evoked and spontaneous gamma and spindle bursts in neonatal rat motor cortex. J. Neurosci. 34, 10870-10883 (2014).

66. Chandrasekaran, A. R., Plas, D. T., Gonzalez, E. \& Crair, M. C. Evidence for an instructive role of retinal activity in retinotopic map refinement in the superior colliculus of the mouse. J. Neurosci. 25, 6929-6938 (2005).

67. Garaschuk, O., Milos, R. I. \& Konnerth, A. Targeted bulk-loading of fluorescent indicators for two-photon brain imaging in vivo. Nat. Protoc. 1, 380-386 (2006).

68. Kummer, M., Kirmse, K., Witte, O. W. \& Holthoff, K. Reliable in vivo identification of both GABAergic and glutamatergic neurons using Emx1Cre driven fluorescent reporter expression. Cell Calcium 52, 182-189 (2012).

69. Stosiek, C., Garaschuk, O., Holthoff, K. \& Konnerth, A. In vivo two-photon calcium imaging of neuronal networks. Proc. Natl Acad. Sci. USA 100, 7319-7324 (2003).

70. Mason, M. J., Simpson, A. K., Mahaut-Smith, M. P. \& Robinson, H. P. The interpretation of current-clamp recordings in the cell-attached patch-clamp configuration. Biophys. J. 88, 739-750 (2005).

\section{Acknowledgements}

We thank Dr Christian A. Hübner and Chuanqiang Zhang for comments on earlier versions of the manuscript, Sindy Beck and Ina Ingrisch for technical assistance and Dr Catherine Clark for language editing. This work was supported by the Priority Program 1665 of the German Research Foundation (HO 2156/3-1 to K.H., KI 1816/1-1 to K.K.), the Federal Ministry of Education and Research (01GQ0923 to K.H., O.W.W.), the Interdisciplinary Centre for Clinical Research Jena (K.K. and K.H.) and the Werner Reichardt Centre for Integrative Neuroscience (CIN, O.G.)

\section{Author contributions}

K.K. and K.H. designed the study with contributions from O.G., Y.K. and O.W.W. K.K and M.K. performed experiments and analysed data. All authors participated in interpretation of data. Initial pilot experiments not included in the final manuscript were performed by O.G., Y.K. and K.K. K.K. and K.H. wrote the manuscript with comments from all authors.

\section{Additional information}

Supplementary Information accompanies this paper at http://www.nature.com/ naturecommunications

Competing financial interests: The authors declare no competing financial interests.

Reprints and permission information is available online at http://npg.nature.com/ reprintsandpermissions/

How to cite this article: Kirmse, K. et al. GABA depolarizes immature neurons and inhibits network activity in the neonatal neocortex in vivo. Nat. Commun. 6:7750 doi: $10.1038 /$ ncomms8750 (2015) 